\title{
LOS FRACASOS POLITICOS Y ELECTORALES DE LA DERECHA ESPAÑOLA: ALIANZA POPULAR, 1976-1986*
}

Hace algo más de diez años pudo decirse de los partidos conservadores europeos que «resisten, pero no triunfan» (Schumann, 1974: 154). Tras la dictadura del general Franco, los partidos conservadores españoles han observado tendencias opuestas e incluso contradictorias. La Unión de Centro Democrático (UCD), un partido conservador reformista según la tipología de LaytonHenry (1982), logró triunfar durante la transición a la democracia, pero fue incapaz de resistir. Como es sabido, UCD obtuvo alrededor del 35 por 100 de los votos en las dos primeras elecciones, formó gobiernos casi mayoritarios y desapareció como consecuencia de su extraordinario fracaso en las elecciones de 1982, en las que su apoyo se redujo drásticamente a un 6 por 100 (tabla 1). Y Alianza Popular (AP), un partido al que la mayoría de los españoles califica de derechas, se ha mantenido en la escena política desde 1976, pero ha sido incapaz de triunfar. Aunque en las elecciones de 1982 AP consiguió convertirse en el segundo partido, multiplicando por cuatro su porcentaje de voto

* Este trabajo es una versión ligeramente abreviada del capítulo que aparecerá en Brian Girvin (ed.), The transformation of contemporary conservatism (Londres: Sage). Debo agradecer a M. Caciagli, R. Gunther, J. J. Linz, H. J. Puhle, G. Sani y J. M. Vallés las valiosas críticas que realizaron a versiones anteriores de este artículo. $Y$ debo reiterar mi agradecimiento al Centro de Investigaciones Sociológicas por las facilidades concedidas para la utilización de su espléndido Banco de Datos. 


\section{TABLA 1}

Resultados de las elecciones para el Congreso de los Diputados, 1977-1986

\begin{tabular}{|c|c|c|c|c|c|c|c|c|}
\hline \multirow[b]{2}{*}{ Partidos } & \multicolumn{2}{|c|}{1977} & \multicolumn{2}{|c|}{1979} & \multicolumn{2}{|c|}{1982} & \multicolumn{2}{|c|}{1986} \\
\hline & $\operatorname{Votos}(\%)$ & Escaños & Votos (\%) & Escaños & Votos (\%) & Escaños & Votos $(\%)$ & Escaños \\
\hline 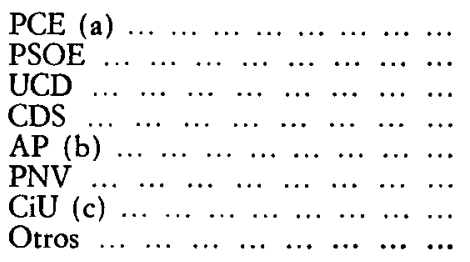 & $\begin{array}{r}9,3 \\
29,9 \\
34,8 \\
-8,4 \\
1,7 \\
3,7 \\
12,7\end{array}$ & $\begin{array}{r}20 \\
118 \\
167 \\
-16 \\
8 \\
11 \\
10\end{array}$ & $\begin{array}{r}10,8 \\
30,5 \\
35,1 \\
-6,1 \\
1,6 \\
2,7 \\
13,2\end{array}$ & $\begin{array}{r}23 \\
121 \\
168 \\
- \\
9 \\
7 \\
8 \\
14\end{array}$ & $\begin{array}{r}3,2 \\
47,3 \\
6,2 \\
2,8 \\
25,9 \\
1,8 \\
3,6 \\
9,2\end{array}$ & $\begin{array}{r}3 \\
202 \\
11 \\
2 \\
107 \\
8 \\
12 \\
5\end{array}$ & $\begin{array}{r}4,7 \\
44,1 \\
-9,2 \\
26,1 \\
1,5 \\
5,0 \\
9,2\end{array}$ & $\begin{array}{r}7 \\
184 \\
-19 \\
105 \\
6 \\
18 \\
11\end{array}$ \\
\hline 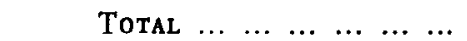 & 100 & 350 & 100 & 350 & 100 & 350 & 100 & 350 \\
\hline
\end{tabular}

(a) En 1986, en la coalición Izquierda Unida.

(b) En 1979, formando Coalición Democrática; en 1982, en coalición con el PDP; en 1986, en la Coalición Popular.

(c) En 1977, Democracia i Catalunya.

Fuentes: Para 1977 y 1979, Linz (1980: 112 y 120); para 1982, Muñoz Alonso et al. (1982: 229); para 1986, El Pais (1987: 71). 
y por doce su representación parlamentaria, se hallaba todavía a una enorme distancia del Partido Socialista Obrero Español (PSOE). Una distancia que se ha mantenido en sus términos cuantitativos tras las últimas elecciones legislativas de 1986, pero que ha aumentado cualitativamente por los efectos combinados de la continuidad de la mayoría parlamentaria del gobierno socialista y de las recientes crisis organizativas y de liderazgo sufridas por AP.

Este trabajo pretende examinar los principales elementos políticos y electorales que han confluido en los fracasos de AP. Las dos primeras secciones del artículo describirán la evolución de AP desde sus comienzos en el confuso panorama organizativo del espectro conservador tras la dictadura franquista hasta su conversión en la segunda fuerza política y en el mayor grupo de oposición al gobierno socialista. La última sección considerará algunos factores intervinientes en la debilidad del conservadurismo español, especialmente los relativos a las posiciones ideológicas y a las imágenes de AP. Aquél parece suponer así una importante excepción en las transformaciones positivas que están experimentando tanto el conservadurismo en Europa como la mayor parte de los partidos conservadores europeos. La situación de AP contrasta con la recuperación intelectual o ideológica, política u organizativa, electoral o gubernamental de sus correligionarios europeos. A diferencia de ellos, AP ha sido por el momento incapaz de superar su déficit de legitimidad democrática y de modernizar sus ofertas ideológicas en una línea más o menos neoconservadora. Como se comprobará a lo largo de estas páginas, las imágenes de AP enfatizan un conservadurismo excesivo (no exento de un cierto autoritarismo) y una rígida defensa de valores tradicionales, en parte incompatibles con una sociedad moderna y secularizada. Las imágenes aliancistas están en la base de sus fracasos políticos y electorales, que a su vez motivan su alejamiento del centro de gravedad ideológica del electorado, justifican su relativamente escaso apoyo electoral (menor de todas formas que el de UCD en 1977-1979) y explican su incapacidad para erigirse en alternativa al gobierno socialista. Resulta así, en definitiva, que, al cabo de la primera década democrática, los viejos problemas históricos de la inarticulación y la debilidad políticas del conservadurismo español siguen todavía sin resolverse satisfactoriamente.

\section{La evolución de AP (I): Resistiendo en los fracasos}

A lo largo de estos sólo diez años, AP ha conocido cambios notables en su organización, identidad política y apoyo electoral. La evolución de AP ha sido tan marcada como para ser considerada una de sus principales características (Montero, 1987; De Esteban y López Guerra, 1982). Su punto de partida radicaba en la observación ya clásica de Duverger (1965: 15): «De igual modo que los hombres conservan durante toda su vida la huella de la infan- 
cia, los partidos sufren profundamente la influencia de sus orígenes.» Pueden señalarse al menos cuatro rasgos de AP que han persistido a lo largo de su proceso de cambios: (i) la extraordinaria importancia del liderazgo de su fundador, Manuel Fraga Iribarne, un ex ministro de la dictadura franquista cuya evolución ideológica ha sido (hasta su dimisión, en diciembre de 1986) en cierto modo paralela a la del partido; (ii) la persistente búsqueda de un espacio electoral e ideológico propio, que en ocasiones ha sido un tanto errática y que aún parece no haber finalizado; (iii) los intentos de maximizar el atractivo del partido mediante una política de coaliciones electorales, en las que AP ha supuesto siempre el núcleo más importante a causa de sus propios recursos, y (iv) la continua reproducción de unas expectativas políticas o electorales casi siempre desorbitadas; unas expectativas que los economistas calificarían de «irracionales» por la frecuencia con la que los líderes conservadores sesgaban sus predicciones o utilizaban sólo una parte de la información.

Los pasos iniciales de AP han sido gráficamente resumidos como «una historia de ambiciones e intenciones frustradas» (Gunther, Sani y Shabad, 1986: 91). AP fue fundada a finales de 1976 como federación de unos llamados «partidos» que en realidad no eran sino proyecciones políticas de antiguos ministros del franquismo ${ }^{1}$. Sus dirigentes esperaban obtener, al parecer, el 50 por 100 de los votos en las primeras elecciones democráticas, convocadas para junio de 1977 (López Pintor, 1985). Pero hubieron de contentarse, sin embargo, con un escaso 8 por 100 y 16 escaños, ocupando una posición subordinada con respecto a UCD y un lugar secundario, casi marginal, del nuevo sistema de partidos (Linz, 1980). El fracaso de AP se debió fundamentalmente a su desconocimiento de la moderación ideológica del electorado español, cuyas preferencias partidistas se dirigieron a partidos de centro-derecha, como UCD, y de centro-izquierda, como el PSOE. Aunque Fraga (1977) pretendía construir un gran partido liberal-conservador que ocupara mediante sus distintos componentes todo el espacio ideológico de centro-derecha, AP fue percibido como un partido situado entre la derecha y la extrema derecha, de naturaleza continuista con el conglomerado ideológico del franquismo y, en consecuencia, de dudosa legitimidad democrática.

Comenzaban así a cristalizar como problemas el estilo de liderazgo y los contenidos de las imágenes políticas de $\mathrm{AP}$, unos problemas que ya no le abandonarían en los años siguientes. AP sobrevaloró el atractivo electoral y organizativo de antiguos «liberales» franquistas, sin darse cuenta que en el marco de la nueva competición democrática aquel «liberalismo» desapareció para dar entrada a unas connotaciones reaccionarias o/y autoritarias. Al mismo

1 De los siete «partidos» federados, seis correspondían a antiguos ministros de la dictadura (el propio Fraga, G. Fernández de la Mora, L. López Rodó, L. de la Fuente, F. Silva Muñoz y C. Martínez Esteruelas) y el séptimo a E. Thomas de Carranza, que había desempeñado altos puestos en la Administración durante el franquismo (López Pintor, 1985). 
tiempo, AP infraestimó su imagen de partido neofranquista, a la que se llegó tanto por la notoria presencia de colaboradores de la dictadura en los niveles de liderazgo nacional o provincial y en las listas de los candidatos como por su propaganda electoral y por las orientaciones políticas de sus propios votantes (López Nieto, 1985; Buse, 1984).

La importancia de estas imágenes para el futuro del partido es evidente. Como puede verse en la tabla 2 , más de dos terceras partes de los electores

\section{TABLA 2}

Imágenes de AP y UCD en el electorado y entre sus respectivos votantes, $1977-1978 *$

(En porcentajes) $* *$

\begin{tabular}{|c|c|c|c|c|}
\hline & IMÁGENE & DE AP & IMÁGENES & DE UCD \\
\hline & $\begin{array}{l}\text { Votantes } \\
\text { de } A P\end{array}$ & $\begin{array}{l}\text { Electo- } \\
\text { rado }\end{array}$ & $\begin{array}{l}\text { Votantes } \\
\text { de UCD }\end{array}$ & $\begin{array}{l}\text { Electo- } \\
\text { rado }\end{array}$ \\
\hline Franquista: & & & & \\
\hline $\begin{array}{llllllllllll}\mathrm{Si}_{1} & \ldots & \ldots & \ldots & \ldots & \ldots & \ldots & \ldots & \ldots & \ldots & \ldots & \ldots\end{array}$ & 73 & 69 & 17 & 33 \\
\hline $\begin{array}{llllllllllll}\text { No } & \ldots & \ldots & \ldots & \ldots & \ldots & \ldots & \ldots & \ldots & \ldots & \ldots & \ldots\end{array}$ & 23 & 10 & 55 & 41 \\
\hline Democrático: & & & & \\
\hline $\begin{array}{llllllllllll}\text { Síl } & \ldots & \ldots & \ldots & \ldots & \ldots & \ldots & \ldots & \ldots & \ldots & \ldots & \ldots\end{array}$ & 47 & 33 & 72 & 61 \\
\hline $\begin{array}{llllllllllll} & \text { No } & \ldots & \ldots & \ldots & \ldots & \ldots & \ldots & \ldots & \ldots & \ldots & \ldots\end{array}$ & 30 & 47 & 5 & 18 \\
\hline $\begin{array}{l}\text { Capaz de evitar la confrontación política en- } \\
\text { tre los españoles: }\end{array}$ & & & & \\
\hline $\begin{array}{llllllllllll}\text { Si }_{1} & \ldots & \ldots & \ldots & \ldots & \ldots & \ldots & \ldots & \ldots & \ldots & \ldots & \ldots\end{array}$ & 36 & 24 & 68 & 47 \\
\hline $\begin{array}{llllllllllll}\text { No } & \ldots & \ldots & \ldots & \ldots & \ldots & \ldots & \ldots & \ldots & \ldots & \ldots & \ldots\end{array}$ & 39 & 53 & 13 & 30 \\
\hline Defensor de valores cristianos: & & & & \\
\hline $\begin{array}{llllllllllll}\mathrm{S}_{1}^{1} & \ldots & \ldots & \ldots & \ldots & \ldots & \ldots & \ldots & \ldots & \ldots & \ldots & \ldots\end{array}$ & 72 & 71 & 70 & 68 \\
\hline $\begin{array}{cccccccccccc}\text { No } & \ldots & \ldots & \ldots & \ldots & \ldots & \ldots & \ldots & \ldots & \ldots & \ldots & \ldots\end{array}$ & 5 & 8 & 6 & 10 \\
\hline Defensor de los empresarios: & & & & \\
\hline $\begin{array}{llllllllllll}\mathrm{S}_{1}^{1} & \ldots & \ldots & \ldots & \ldots & \ldots & \ldots & \ldots & \ldots & \ldots & \ldots & \ldots\end{array}$ & 70 & 74 & 60 & 65 \\
\hline $\begin{array}{llllllllllll}\text { No } & \ldots & \ldots & \ldots & \ldots & \ldots & \ldots & \ldots & \ldots & \ldots & \ldots & \ldots\end{array}$ & 7 & 6 & 15 & 13 \\
\hline Defensor de los trabajadores: & & & & \\
\hline $\begin{array}{llllllllllll}\text { Sí } & \ldots & \ldots & \ldots & \ldots & \ldots & \ldots & \ldots & \ldots & \ldots & \ldots & \ldots\end{array}$ & 25 & 15 & 60 & 36 \\
\hline $\begin{array}{llllllllllll}\text { No } & \ldots & \ldots & \ldots & \ldots & \ldots & \ldots & \ldots & \ldots & \ldots & \ldots & \ldots\end{array}$ & 52 & 64 & 17 & 42 \\
\hline $\begin{array}{lllllllllll}(n) & \ldots & \ldots & \ldots & \ldots & \ldots & \ldots & \ldots & \ldots & \ldots & \ldots\end{array}$ & $(381)$ & $(5.898)$ & $(1.573)$ & $(5.898)$ \\
\hline
\end{tabular}

* La imagen relativa al «franquismo" está referida a los votantes de AP y UCD de Madrid en 1977; las demás, a los votantes potenciales de AP y UCD de toda España en 1978. El número de casos se refiere sólo a la encuesta de 1978.

* No se han incluido los porcentajes de no respuesta.

Fuente: Adaptado de Linz et al. (1981: 472 y 483). 
consideraban a AP un partido franquista, y cerca de la mitad no lo estimaba democrático ni capaz de evitar la confrontación política de los españoles; tres cuartas partes lo concebían como defensor de los valores cristianos y de los empresarios en medida aún mayor de la que le negaban la defensa de los trabajadores. Aunque comparta con AP alguna de estas imágenes, UCD había logrado asentar su legitimidad democrática en mucha mayor medida. Los votantes de UCD se diferenciaban también de los de AP en sus perfiles ideológicos. La inmensa mayoría de los de AP, por ejemplo, manifestaba opiniones positivas o muy favorables sobre la reciente dictadura, una amplia mayoría escogía el orden antes que la libertad como mejor expresión de sus ideas y casi la mitad se declaraba ideológicamente continuador del franquismo (Linz et al., 1981). De ahí que AP fuera situada por el electorado en la posición media 4,3 de una escala ideológica izquierda-derecha de 5 puntos, mientras que la de UCD era de 3,2 , mucho más cercana a la posición media del propio electorado, en el $2,7^{2}$.

Aquellas imágenes y estas actitudes frustraron sus ambiciones de constituirse en el gran partido liberal-conservador que se moviera entre el PSOE y la extrema derecha. Anulada electoralmente por una UCD que había logrado conectar con la moderación ideológica de los españoles, AP intentó durante 1978-1979 moderar sus postulados ideológicos y abandonar sus rasgos de partido antisistema. Y lo hizo sobre todo mediante su intervención en el proceso constituyente abierto tras las elecciones de 1977. En primer lugar, la participación de Fraga en la ponencia constitucional supuso una excelente ocasión para mejorar a su través la imagen del partido; sus consecuencias para la reducción del déficit de legitimidad democrática de AP fueron, en opinión de Fraga (1982: 78), claramente positivas. En segundo lugar, el grupo parlamentario de AP quedó dividido a la hora de votar la Constitución. Pese al carácter reticente y condicionado del voto afirmativo del sector representado por Fraga, el voto frontalmente negativo del otro sector permitió a AP alejarse del denominado «franquismo histórico». La escisión permitió también la coalición de AP con grupos y personas pertenecientes a la derecha moderada que, ante la inminencia de unas nuevas elecciones generales, ampliaran la base electoral conservadora. Pudo nacer así, en los primeros meses de 1979, Coalición Democrática (de ahora en adelante, AP-CD), formada por AP y por pequeños «partidos» de notables conservadores (sobre todo liberales y democristianos) que no se habían integrado en $\mathrm{UCD}^{3}$.

Los resultados de AP-CD en las elecciones legislativas de marzo de 1979

2 Estos datos proceden de la encuesta realizada por el Centro de Investigaciones Sociológicas (CIS) en junio de 1978 a una muestra representativa nacional de 5.345 españoles mayores de edad; los datos están depositados en el Banco de Datos del CIS.

${ }^{3}$ Entre esos notables destacaban José María de Areilza, ex ministro de Asuntos Exteriores en el primer gobierno de la Monarquía, y Alfonso Osorio, ex vicepresidente de los primeros gobiernos de A. Suárez. 
constituyeron un nuevo fracaso, superior incluso al de 1977. Obtuvo sólo el 6 por 100 de los votos y nueve escaños: demasiado pocos para las varias decenas que al parecer pensaba recibir. De nuevo, las grandes expectativas de AP se vieron espectacularmente reducidas. No sólo continuaba ocupando el último lugar entre los partidos nacionales, sino que había perdido incluso 400.000 votos (pese al aumento del censo por la inclusión de los mayores de 18 años). En 45 de las 52 circunscripciones, AP-CD se convirtió en un partido extraparlamentario. Al menos una cuarta parte de los electores de AP en 1977 transfirió su voto de 1979 a UCD, y un 5 por 100 a los candidatos de extrema derecha (Montero, 1987; Gunther, Sani y Shabad, 1986: 350). Estos desplazamientos eran, además, excepcionales en el marco del comportamiento electoral de 1979, que ha sido caracterizado precisamente por una considerable rigidez del voto y por unas escasas transferencias interpartidistas (Santamaría, 1982: 413).

En un importante esfuerzo para modificar su imagen, AP-CD se autodefinió como una coalición de centro-derecha, con un programa político inequívocamente conservador, pero democrático, y con un programa económico de corte neoliberal. Su estrategia radicó en competir con UCD por los espacios centrales del espectro ideológico, donde se situaba la mayoría de los españoles. Y sus tácticas consistieron en enfatizar la moderación de sus ofertas programáticas, acusar de «izquierdismo» a la política gubernamental de UCD y contrarrestar los efectos del «voto útil» que realizaron sus competidores (Sani, Gunther y Shabad, 1981; García Morillo, 1979). Pero el esfuerzo de readaptación de AP-CD resultó, sin embargo, insuficiente. Los cambios ideológicos de AP desde 1977 y la creación de Coalición Democrática no sólo no pudieron atraer al electorado centrista, sino que tampoco lograron modificar las imágenes que situaban a AP-CD en el ámbito de una derecha excesivamente conservadora y autoritaria, $y$, por lo tanto, inaceptable para muchos españoles. Como la ha descrito Espín (1979: 78),

«Coalición Democrática ha venido a representar en 1979 lo que AP dos años antes: una coalición electoral cuya intención última era la unificación de un partido que representase la derecha tradicional española (...). La orientación programática de CD (..) ha sido una defensa de los valores tradicionales en materia social, de los intereses más conservadores en materia económica y de un franquismo evolucionado en lo político (...). Dentro de este contexto programático centró su atención en puntos como la defensa de la familia, el orden público, un regionalismo muy moderado, defensa de los intereses empresariales, etc.»

El fracaso de la estrategia de AP-CD contrastaba con el éxito de UCD, que había logrado revalidar el apoyo de su electorado. Como muestra de su éxito, UCD consiguió convertirse en la opción política mayoritaria entre los 
sectores ideológicos del centro-derecha, derecha y extrema derecha; la tabla 3 es significativa a este respecto ${ }^{4}$. AP-CD, en cambio, sólo pudo obtener sus mejores resultados relativos en los espacios ideológicos en los que se situaba una menor proporción, en ocasiones mínima, del electorado. El panorama del conservadurismo español parecía cristalizarse así alrededor de dos fuerzas políticas, UCD y AP, aparentemente destinada la primera a continuar disfrutando de la posición preeminente debido a su carácter centrista y a su naturaleza moderada, y condenada la segunda a seguir ocupando un lugar subordinado con respecto a UCD y marginal en el sistema de partidos a causa de su excesivo conservadurismo. No obstante, los acontecimientos que se produjeron entre 1979 y 1982 habrían de modificar radicalmente el propio sistema de partidos y la correlación de las fuerzas conservadoras, llevando nada menos que a la desaparición de UCD y al protagonismo exclusivo de AP dentro del campo conservador.

\section{TABLA 3}

Voto a AP-CD, UCD y PSOE según la autoubicación ideológica del electorado en la escala izquierda-derecha, 1979

(En porcentajes horizontales) *

\begin{tabular}{|c|c|c|c|c|c|c|}
\hline & & & Voto a & & & \\
\hline & & $A P \cdot C D$ & $U C D$ & PSOE & $(n) * x$ & Electorado \\
\hline $\begin{array}{l}\text { Extrema } \\
\text { izquierda }\end{array}$ & 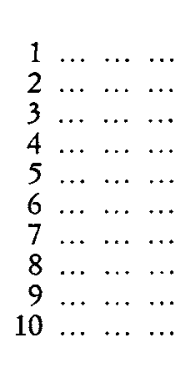 & $\begin{array}{r}- \\
1 \\
2 \\
2 \\
6 \\
16 \\
17 \\
28 \\
15\end{array}$ & $\begin{array}{r}7 \\
2 \\
2 \\
10 \\
71 \\
82 \\
71 \\
72 \\
57 \\
67\end{array}$ & $\begin{array}{r}33 \\
47 \\
67 \\
80 \\
25 \\
9 \\
8 \\
5 \\
7 \\
6\end{array}$ & $\begin{array}{l}(111) \\
(131) \\
(440) \\
(446) \\
(876) \\
(368) \\
(172) \\
(195) \\
(49) \\
(70)\end{array}$ & $\begin{array}{r}6 \\
5 \\
15 \\
16 \\
31 \\
12 \\
5 \\
6 \\
1 \\
2\end{array}$ \\
\hline
\end{tabular}

* Se ha excluido la no respuesta de la base de los porcentajes; éstos pueden no sumar cien debido a que se han seleccionado los votantes de tres partidos.

** El número de casos está integrado sólo por los votantes de AP-CD, UCD, PSOE, PCE y Unión Nacional en cada una de las posiciones de la escala ideológica.

Fuente: Encuesta DATA, 1979.

4 Los datos de la tabla 3 proceden de la encuesta postelectoral realizada por DATA en 1979 a una muestra representativa nacional de 5.439 españoles mayores de edad; a ella nos referiremos en lo sucesivo como Encuesta DATA, 1979. La encuesta fue dirigida por R. Gunther, G. Sani y G. Shabad, de la Ohio State University, a quienes agradezco las facilidades concedidas por su consulta y utilización. 


\section{La evolución de AP (II): Resistiendo sin triunfar}

Pese al reducido tamaño de su grupo parlamentario, AP desempeñó un papel importante en la legislatura de 1979. A ello contribuyeron la relativa debilidad parlamentaria de UCD y la relativa fuerza del PSOE, así como la ausencia entre ambos de partidos menores que pudieran prestar su apoyo alternativo a uno u otro para la formación de gobiernos mayoritarios (Linz et al., 1981). Además, el peso político de AP fue aumentando progresivamente a lo largo de la legislatura de la mano de dos factores complementarios: la reorganización del partido, comenzada poco después de las elecciones legislativas de 1979, y la paulatina descomposición de UCD, sustanciada en las diversas elecciones regionales que se convocaron entre marzo de 1980 y mayo de 1982. Poco después, las elecciones generales de octubre de 1982 rubricaron, como ya se ha dicho, la desaparición de UCD y la transformación de AP en la segunda fuerza política de un nuevo sistema de partidos.

El III Congreso Nacional, celebrado en diciembre de 1979, significó el comienzo de un intenso proceso de cambios; un dirigente aliancista lo ha calificado acertadamente como un Congreso «decisivo en la historia del partido» (Calero, 1985: 207). En primer lugar, AP se dotó de una estructura fuertemente presidencialista, que consagró el liderazgo de Fraga. En segundo lugar, AP huyó tanto de las etiquetas ideológicas relacionadas con el centro-derecha, a las que culpaba de su último fracaso electoral, como de las derivadas de la derecba, cuya vinculación con el pasado dictatorial le otorgaba una carga negativa. Los términos escogidos redefinieron a AP como un partido liberalconservador, a los que se añadieron los de reformista, popular y democrático. Con ellos se pretendía construir una nueva derecba que fuera capaz de combinar su conservadurismo con las ofertas interclasistas de un partido típicamente catch-all. Su modelo se cifraba en la mayoría presidencial francesa (antes de 1981) o en los grandes partidos conservadores anglosajones. Pero su contenido seguía resaltando, sin embargo, los perfiles habituales del discurso ideológico de la derecha española: la unidad de la patria y el centralismo; los principios de «ley y orden» y la concepción de un Estado «fuerte»; la moral «antimaterialista» y la supremacía de la «civilización cristiana»; la defensa de las "grandes instituciones sociales», como la familia, la Iglesia o el ejército; los valores tradicionales en temas relativos al divorcio o aborto (Fraga, 1981; Del Aguila y Montoro, 1984). Y, en tercer lugar, formuló su estrategia política alrededor de la «mayoría natural», de contornos mucho más retóricos e imprecisos. Realizada ya la transición a la democracia, AP creía necesaria la simplificación del sistema de partidos, de modo que sea posible la alternancia de sólo dos grandes opciones políticas incardinadas en un esquema bipartidista, y dentro del cual el espacio «natural» y «mayoritario» correspondía al de AP. Para los líderes de AP, el «centro» no existía ideológica ni políticamente, ni podía tener tampoco representación partidista propia. 
La competición con el PSOE debería hacerse, entonces, por la derecha, en la que además, según los mismos dirigentes conservadores, se asentaba la mayoría de los españoles. El objetivo de la «mayoría natural» buscaba, pues, tanto conseguir el voto del electorado conservador que había escogido "provisionalmente» a UCD como, a la vez, desgajar de la «artificial» coalición de UCD a los grupos políticos cuyo evidente conservadurismo propiciaba su vinculación «natural» con la línea ideológica de AP.

Es probable que, por segunda vez en su corta historia, los líderes de AP estuvieran equivocándose al señalar un objetivo inalcanzable y al prever unos mecanismos de mediación irreales. El diseño estratégico de la «mayoría natural» no tenía en cuenta la distribución básicamente centrista (y ligeramente izquierdista) de las preferencias ideológicas del electorado, e ignoraba también las diferencias actitudinales que separaban a los votantes de UCD de los de AP. Sin embargo, el planteamiento aliancista pareció funcionar durante este período. El progresivo afianzamiento organizativo de AP contrastaba con la creciente descomposición de UCD. Por si no bastara con sus propios conflictos internos, la crisis de UCD se vio, además, impulsada por la acción de los entonces denominados poderes fácticos, que alentaron la sustitución a corto plazo de UCD sobre la base del liderazgo de Fraga y de la alternativa de AP (Hunneus, 1985; Gunther, 1986 b; Caciagli, 1986: 233). Entre aquéllos tuvo una especial importancia la Confederación Española de Organizaciones Empresariales (CEOE), cuyos dirigentes compartieron con AP los supuestos erróneos sobre el crecimiento inmediato aliancista y sobreestimaron, en cualquier caso, el apoyo de las opciones conservadoras incluso entre sus asociados (Martínez, 1984). Las elecciones autonómicas de Galicia y Andalucía ofrecieron los síntomas iniciales del hundimiento irreversible de UCD, de su sustitución gubernamental por el PSOE y de la ocupación por AP de una parte sustancial del espacio no socialista (Portero, Blanco y Maiz, 1982; Porras, 1985; López Pintor, 1982). Y las generales de octubre de 1982 los confirmaron plenamente.

Como en 1979, AP se presentó formando el principal núcleo de una nueva coalición; en este caso con varios partidos regionales y con el Partido Demócrata Popular (PDP), fundado poco antes por un grupo de notables y parlamentarios pertenecientes al sector democristiano de UCD (Hunneus, 1985; Montero, 1987). Sin duda, los resultados obtenidos por AP-PDP fueron espectaculares. Pasó del millón de votos, aproximadamente, de 1979 a algo más de cinco millones y medio; su cerca del 26 por 100 del voto hizo crecer su representación parlamentaria de nueve diputados a 107. Mientras que en 1979 AP-CD se vio reducida a la condición de extraparlamentaria en 45 circunscripciones, la coalición AP-PDP obtuvo al menos un escaño en prácticamente todas ellas. Y si en 1979 AP-CD sólo consiguió ocupar la segunda posición en dos circunscripciones, y la tercera en 18, AP-PDP logró ser el primer partido en siete distritos, y el segundo en los restantes, excepto en el País 
Vasco y Cataluña, donde quedó relegada a posiciones inferiores. La mayor transferencia de voto recibida por AP-PDP provino, obviamente, de UCD, de cuyo electorado de 1979 entre el 48 por 100 (tres millones de votos) y el 40 por 100 (dos millones y medio de votos) dirigieron sus nuevas preferencias políticas hacia la coalición conservadora (Sani, 1986; Maravall, 1984; Caciagli, 1986; López Pintor y Justel, 1982). En un contexto caracterizado por la enorme magnitud de la volatilidad electoral y por el considerable incremento de la participación (Maravall y Santamaría, 1985; Bar, 1985; Montero, 1984 y 1986 a), AP-PDP recibió también las dos terceras partes de los votantes de las fuerzas políticas de extrema derecha, lo que motivó que se disolvieran poco después de las elecciones. Como consecuencia de todo ello, la composición del electorado de AP-PDP aparecía mayoritariamente formada por los antiguos votantes de UCD, mientras que los «leales» a AP (quienes le votaron en 1979 y 1982) constituían sólo una tercera parte.

Las distintas dimensiones del éxito de AP-PDP han sido calificadas con razón como «la novedad más importante de estas elecciones» (Caciagli, 1986: 168). Pero cabe también relativizar aquéllas desde un doble punto de vista, confluyente en lo que podría denominarse su «sub-triunfo» electoral (Montero, 1986 b). De un lado, el fracaso, por lo demás fácilmente previsible, de la estrategia conservadora de la «mayoría natural». En contra de las previsiones de AP, entre un 16 y un 27 por 100 de los antiguos votantes de UCD se dirigieron al PSOE. AP-PDP hubo de conformarse, además, con 800.000 votos menos que UCD en 1979, lo que, unido al extraordinario crecimiento electoral del PSOE (Puhle, 1986), aumentó las diferencias entre los dos principales partidos. Si en 1979 la distancia entre UCD y PSOE no superaba los cinco puntos porcentuales y unos 50 escaños, en 1982 el PSOE lograba una diferencia de más de 20 puntos porcentuales con respecto a AP-PDP (más de cuatro millones y medio de votos) y casi doblaba su número de escaños. $\mathrm{Y}$, de otro lado, el relativo fracaso de los intentos de AP-PDP para copar todo el espacio partidista de centro-derecha y derecha. Como puede observarse en la tabla $4^{5}$, el importante crecimiento de AP-PDP en los sectores de la derecha y extrema derecha (que suponían, aproximadamente, sólo una quinta parte de las preferencias ideológicas del electorado) se combinaba con su incapacidad para sustituir a UCD en sectores específicos del centro (en el que se situaba, en cambio, cerca de la tercera parte del electorado). De lo que se deducía que el hipotético acceso de AP-PDP al gobierno dependería de su habilidad para captar, por sí misma o en coalición con otras fuerzas no socia-

${ }^{5}$ Los datos de la tabla 4 pertenecen a la encuesta postelectoral realizada por DATA en el otoño de 1982 a una muestra representativa nacional de 5.463 españoles mayores de edad; a ella nos referiremos en lo sucesivo como Encuesta DATA, 1982. A su vez, la encuesta forma parte de una investigación sobre las elecciones legislativas de 1982 financiada por la Stiftung Volkswagenwerk, de la República Federal de Alemania, y realizada por J. J. Linz, H.-J. Puhle, R. Gunther, G. Sani, G. Shabad, P. del Castillo y el autor; puede verse, al respecto, Linz y Montero (1986). 


\section{TABLA 4}

Voto a AP-PDP, UCD, CDS y PSOE según la autoubicación ideológica del electorado en la escala izquierda-derecba, 1982

(En porcentajes horizontales) *

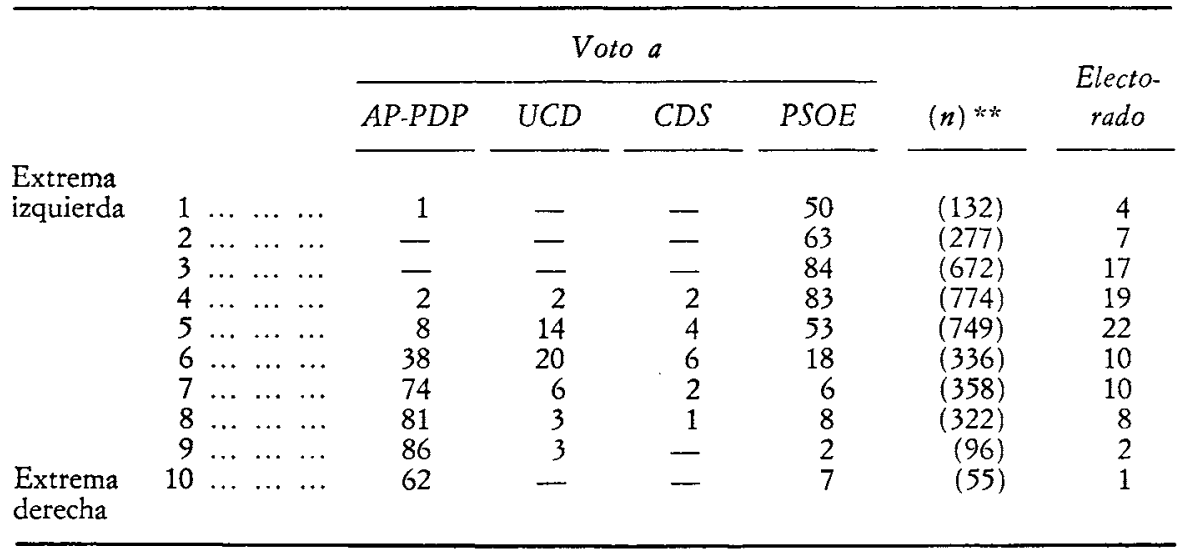

* Se ha excluido la no respuesta de la base de los porcentajes. Estos pueden no sumar cien debido a que se han seleccionado los votantes de cuatro partidos.

** El número de casos está integrado sólo por los votantes de AP-PDP, UCD, CDS, PSOE, PCE y FN, y por los abstencionistas, en cada una de las posiciones de la escala ideológica.

FUENTE: Encuesta DATA, 1982.

listas, los votos del espacio ideológico central. Las próximas confrontaciones electorales girarán, según veremos, alrededor de esos supuestos.

La naturaleza excepcional del realineamiento del sistema de partidos español ocurrido en 1982 planteaba numerosos interrogantes sobre su futura estabilidad (Gunther, 1986 a; Santamaría, 1984; Bar, 1985). Pero de ellos no cabía deducir, como hicieron los líderes aliancistas, que AP-PDP había sustituido definitivamente a UCD en la nueva fase «bipartidista» del sistema de partidos, por lo que era sólo cuestión de tiempo el que los sectores centristas que habían votado al PSOE o a la misma UCD en octubre de 1982 se dirigieran necesariamente hacia AP en el futuro para facilitarle así el acceso al gobierno. De hecho, la lectura que efectuaron de los resultados electorales de 1982 partía de tres presupuestos erróneos. En primer lugar, los líderes conservadores malinterpretaron la principal causa de la volatilidad electoral producida en 1982; a su juicio, la enorme magnitud de cambio de voto se había debido fundamentalmente a la modificación del mapa ideológico de los españoles, y no tanto a la crisis del PCE o a la desintegración de UCD, que obligaron a sus antiguos votantes a reorientar sus preferencias electoralas (Sani 
y Shabad, 1986). En segundo lugar, subestimaron las diferencias actitudinales e ideológicas que separaban a su propio electorado del de los partidos de centro-derecha (como UCD y el Centro Democrático y Social [CDS]); pese a la multitud de indicadores que atestiguaba la existencia de dos electorados distintos, los líderes de AP optaron por el intento de encauzarlos en un solo partido, que ocupara además todo el espacio político a la derecha del PSOE (Maravall y Santamaría, 1985). En tercer lugar, y como consecuencia de los anteriores, sobrevaloraron los resultados «bipartidistas» de las elecciones de 1982; para ellos, la desaparición de UCD cerraba una etapa transitoria tras la cual los dos grandes partidos de la izquierda (PSOE) y la derecha (AP) competirían entre sí de forma estable, duradera y, ausente ya el «artificio» centrista, «natural». Podrían cumplirse así los deseos conservadores, difundidos insistentemente por Fraga desde 1980, de lograr la eliminación del mapa partidista de una fuerza centrista que no hacía más que imposibilitar la formación de la «mayoría natural» de los españoles en torno a un único partido de derecha, y de importar el modelo anglosajón de fuerzas políticas mediante la reducción del caso español a sólo dos grandes partidos que articularan, respectivamente, los dos «modelos de sociedad» que se enfrentan en los países occidentales (Fraga Iribarne, 1981 y 1983).

Después de las elecciones de octubre de 1982, los líderes de AP tenían cuatro años por delante para desarrollar estos tres supuestos. Resulta evidente, sin embargo, que al cabo del tiempo ninguno de ellos cristalizó en la forma que esperaban. Ni el electorado español había modificado su moderación ideológica mediante un desplazamiento parcial hacia la derecha, ni el electorado centrista se mostraba dispuesto a incorporarse a la coalición conservadora salvando las divergencias ideológicas que les separaban, ni la propia coalición logró la articulación en su interior de toda la oposición antisocialista. Es probable que el fracaso de los objetivos estratégicos de AP lo fuera tanto más cuanto mayores habían sido las expectativas generadas por unos éxitos más aparentes que reales. Lo cierto es que AP-PDP no sólo fue incapaz de imponerse al PSOE en las numerosas consultas «intermedias» celebradas durante el período $1983-1985^{\circ}$, sino que tampoco consiguió atraerse el voto centrista; la permanencia de distintos partidos centristas de ámbito nacional o regional se combinó con la continuidad de lo que se llamó el «techo» electoral de AP-PDP, situado entre el 25 y el 30 por 100 del voto (Montero, $1986 b$ y 1987).

- Esas elecciones comprendían las locales y autonómicas de mayo de 1983, las autonómicas del País Vasco y Cataluña de febrero y abril, respectivamente, de 1984 y las autonómicas de Galicia de 1985. AP-PDP perdió las primeras ante el PSOE, quedando en tercera posición, y en las autonómicas vascas y catalanas, tras los respectivos partidos regionales PNV y CiU y el PSOE; tan sólo en Galicia, uno de sus feudos tradicionales, pudo ganar, pero sin obtener la mayoría absoluta que los líderes conservadores habían vaticinado, y sin canalizar tampoco los votos del partido centrista regional (Montero, 1987; Llera Ramo, 1985; Equip de Sociologia Electoral, 1987; Laraña, 1986). 
Los líderes conservadores fracasaron, asimismo, en sus intentos de articular una «gran coalición» que integrara a todos los partidos a la derecha del PSOE y que facilitara su derrota en las elecciones legislativas previstas para 1986. La coalición conservadora conoció sólo pequeños cambios: pasó a denominarse Coalición Popular (a la que nos referiremos en adelante como AP$\mathrm{CP}$ ) por la presencia de un nuevo «partido», el Partido Liberal (PL), un grupo en realidad inexistente e impulsado desde la propia AP. La nueva Coalición Popular integraba, así, a AP, junto con el PDP y el PL, los cuales, sin apoyos electorales conocidos, tenían la imposible misión de «centrar» el conservadurismo de la coalición. La política de oposición al gobierno durante esta legislatura no mejoró un panorama que seguía siendo negativo para las expectativas conservadoras. Sobre todo porque AP-CP desaprovechó la oportunidad de su permanencia en la oposición para llevar a cabo una imprescindible tarea de relanzamiento intelectual y cambio ideológico, como hicieron otros partidos conservadores europeos en situaciones similares. Además, la oposición institucional de AP-CP ejercitó un considerable absentismo, se caracterizó por una cierta apatía y se movió a remolque del gobierno. Las excepciones a esta regla consistieron en acciones parlamentarias que criticaban la gestión gubernamental en términos apocalípticos o catastrofistas, tratando de deslegitimar su política de reformas (una política que, por lo demás, contaba con el apoyo mayoritario del electorado). No resulta extraño, por ello, que, según numerosos datos de encuestas realizadas en este período, dos terceras partes de los españoles opinaran que AP-CP colaboraba poco o nada a la solución de los problemas, o que una mayoría considerase a AP-CP una coalición demasiado extremista y, en consecuencia, poco preparada para gobernar (Montero, 1987). El colofón de todo ello provino de la postura de «abstención activa» adoptada por AP$\mathrm{CP}$ en el referéndum sobre la permanencia española en la OTAN; una postura tan confusa, contradictoria y oportunista como para no ser compartida por sus aliados conservadores europeos, ni seguida unánimemente por los líderes intermedios de AP-CP, ni siquiera obedecida por sus propios votantes (Equip de Sociologia Electoral, 1986).

El planteamiento de las elecciones legislativas de junio de 1986 certificó el fracaso de las premisas estratégicas conservadoras: la articulación del electorado no socialista se haría nuevamente mediante la doble alternativa de centro (a través de ofertas como las del CDS y el Partido Reformista Democrático [PRD] en el nivel nacional y del PNV y CiU en los regionales) y de derecha (a través de AP-CD). Su principal incógnita residía en qué alternativa saldría triunfante de esta competición, y en qué términos electorales quedaría cifrada la división entre el centro y la derecha. Los temas más importantes de la campaña se redujeron a otras dos incógnitas complementarias. De un lado, los intentos por evitar la repetición de una mayoría absoluta parlamentaria por parte del PSOE. De otro, el futuro que aguardaba a la propia Coalición Popular: si se cumplían sus habituales (y también desmesuradas) previsiones 
positivas, por los pactos postelectorales que tendría que realizar con partidos de centro para la formación de un gobierno no socialista, $y$, si se quedaban cortas, por la ruptura que ya había anunciado alguno de los partidos menores coligados, o por el incierto futuro que aguardaba a quien hasta entonces aparecía como su máximo líder, Fraga Iribarne.

La falta de renovación intelectual de AP-CP y su propensión a las actuaciones políticas a muy corto plazo hicieron de la campaña conservadora un excelente indicador de unas dimensiones ideológicas y políticas muy alejadas del centro de gravedad del electorado. Las ofertas programáticas o/y propagandísticas de AP-CP volvieron a basarse en un «liberal-conservadurismo» cuyo contenido se compadecía mal con su formato. Pese a sus intentos explícitos de realizar una campaña «sosegada» y carente de ataques a sus adversarios, que fue caracterizada como de «mano de hierro con guante de raso», la mayor parte de sus contenidos se saldó con las ya habituales descripciones catastrofistas de la situación y las visiones apocalípticas del futuro en caso de victoria socialista. La moderación que pretendía imprimirse a sus promesas se difuminaba con mayor fuerza aún por el acusado conservadurismo de la mayoría de los candidatos, que desplazaron a la derecha el programa oficial de la coalición. Y los esfuerzos para dotar a la alternativa liberal-conservadora de sentido «constructivo» terminaron por desaparecer ante los frecuentes enjuiciamientos del gobierno socialista con la radicalidad de un «cero absoluto». Entre las modificaciones legislativas que AP-CP pensaba acometer en el supuesto de su victoria, se excluía la despenalización del aborto, pero se incluía las importantes reformas legislativas llevadas a cabo por el gobierno socialista en temas tan importantes como la educación o la fiscalidad. La prioridad otorgada a estas cuestiones posponía nuevamente los planes conservadores relativos a la reforma constitucional. Entre sus políticas futuras destacaba la defensa de la libertad, de la seguridad y de la igualdad de oportunidades, pero también la ilegalización de Herri Batasuna y la vaga promesa de acabar en seis meses con el terrorismo, dentro todo ello de la concepción usual conservadora de un «Estado fuerte». El neoliberalismo económico estaba presente en sus intenciones de reducir la presión fiscal y el gasto público, privatizar las empresas públicas y la gestión de servicios asistenciales básicos. En fin, sus promesas de lograr la plena integración española en la estructura militar de la OTAN resultaban difíciles de casar con su postura abstencionista en el reciente referéndum. De forma similar, el acentuado populismo con el que caracterizaba a los destinatarios de sus ofertas se contradecía con el dato de que el programa de AP.CP coincidiera «en un 90 por 100 » con el de la organización empresarial CEOE (Montero, 1987).

Los resultados electorales de junio de 1986 significaron una nueva decepción para los ambiciosos proyectos de AP-CP. Pese al incremento del censo en más de dos millones de electores, los 5,2 millones de votos obtenidos por la Coalición implicaban una pérdida de más de 300.000 con respecto a octubre 
de 1982. En unos comicios caracterizados por el descenso de la participación en nueve puntos porcentuales y por la continuidad básica de la distribución de las preferencias electorales, AP-CP sólo pudo hacerse con el 26,1 por 100 de los votos válidos. Ello supuso 195 diputados (uno menos que en 1982), de los que 21 pertenecían al PDP y 12 al PL, y 63 senadores ( 9 más que en 1982), de los que 11 eran del PDP y 8 del PL ${ }^{7}$. Tras las expectativas depositadas en un crecimiento que llegaría incluso hasta la alternancia gubernamental, la continuidad del voto de AP-CP no pudo por menos que suscitar apreciaciones negativas. Esa continuidad resultaba sólo paliada por el fracaso absoluto del PRD (algo menos del 1 por 100 de los votos), pero contrastaba con el ascenso del CDS (del 2,8 al 9,2 por 100) y con el mantenimiento de la mayoría absoluta parlamentaria por parte del PSOE (pese a reducir sus porcentajes de voto del 47,3 al 44,3 por 100). Además, AP-CP seguía manteniéndose a gran distancia del PSOE: nada menos que por debajo de tres millones de votos, que suponían una diferencia de 18 puntos porcentuales. Junto a la repetición del fracaso por encauzar una «mayoría natural», que si acaso apoyaba al PSOE, Coalición Popular se mostró también, evidentemente, incapaz de hacerse con el espacio electoral existente a la derecha del PSOE. Tanto en 1982 como en 1986, los votos de la Coalición no lograron siquiera alcanzar los de UCD de 1977 y 1979. En 1982, los partidos centristas (el nuevo CDS y una UCD en trance ya de desaparición, la CiU y el PNV) consiguieron alrededor de tres millones de votos; cuatro años después, esa cantidad se había elevado ligeramente, repartiéndose casi a partes iguales entre el CDS, de un lado, y PNV y, sobre todo, CiU, de otro. Se recogían así los frutos, entre otros factores, de una estrategia errónea para atraerse a los votantes centristas, en cuanto que desconocía injustificadamente las diferencias que separaban a aquéllos del electorado conservador (Del Castillo y Sani, 1986; Payne, 1986; Leguina, 1986; Díez Nicolás, 1986; Roberts, 1986). Como puede finalmente comprobarse en la tabla 5, los esfuerzos de AP-CP para aumentar su presencia entre los sectores ideológicos centristas resultaron, según cabía esperar, infructuosos ${ }^{8}$. Aunque con algunas variaciones, la distribución en 1986 de las preferencias electorales en los distintos sectores ideológicos no modifica sustancialmente la de 1982 (véase supra, tabla 4). La fuerza de la Coalición seguía siendo abrumadora en los espacios de la derecha y de la extrema derecha, que recogía sólo a una séptima parte del electorado, pero era claramente inferior en los espacios que agrupaban, en cambio, a proporciones mucho más numerosas de votantes. Tras los frecuentes intentos realizados desde 1982, la pretensión de AP-CP de ocupar todo el espacio desde

7 Debe señalarse que la convocatoria de las elecciones legislativas de junio de 1986 coincidió con la de las autonómicas para el Parlamento de Andalucía, cuyos resultados no variaron sustancialmente de los nacionales (Soria Medina, 1986).

- Los datos de la tabla 5 proceden de la encuesta postelectoral realizada por el CIS en julio de 1986 a una muestra representativa nacional de 8.236 españoles mayores de edad. 
TABLA 5

Voto a Coalición Popular, CDS, PSOE e Izquierda Unida según la autoubicación ideológica de los votantes en la escala izquierda-derecha, 1986

(En porcentajes horizontales) *

\begin{tabular}{|c|c|c|c|c|c|c|c|}
\hline & & \multicolumn{4}{|c|}{ Voto a } & \multirow[b]{2}{*}{$(n) * *$} & \multirow{2}{*}{$\begin{array}{c}\text { Electo- } \\
\text { rado }\end{array}$} \\
\hline & & $C P$ & $C D S$ & PSOE & $I U$ & & \\
\hline $\begin{array}{l}\text { Extrema } \\
\text { izquierda }\end{array}$ & $\begin{array}{rlll}1 & \ldots & \ldots & \ldots \\
2 & \ldots & \ldots & \ldots \\
3 & \ldots & \ldots & \ldots \\
4 & \ldots & \ldots & \ldots \\
5 & \ldots & \ldots & \ldots \\
6 & \ldots & \ldots & \ldots \\
7 & \ldots & \ldots & \ldots \\
8 & \ldots & \ldots & \ldots \\
9 & \ldots & \ldots & \ldots \\
10 & \ldots & \ldots & \ldots \\
1 & \ldots & \ldots\end{array}$ & $\begin{array}{l}1 \\
- \\
\overline{10} \\
51 \\
82 \\
91 \\
95 \\
90\end{array}$ & $\begin{array}{r}1 \\
1 \\
6 \\
40 \\
32 \\
9 \\
2 \\
2 \\
5\end{array}$ & $\begin{array}{r}54 \\
63 \\
87 \\
90 \\
46 \\
11 \\
7 \\
4 \\
3 \\
5\end{array}$ & $\begin{array}{r}36 \\
29 \\
10 \\
3 \\
1 \\
- \\
- \\
- \\
-\end{array}$ & $\begin{array}{r}(147) \\
(358) \\
(1.048) \\
(1.227) \\
(803) \\
(320) \\
(274) \\
(220) \\
(118) \\
(103)\end{array}$ & $\begin{array}{r}3 \\
8 \\
21 \\
24 \\
21 \\
8 \\
6 \\
4 \\
2 \\
2\end{array}$ \\
\hline
\end{tabular}

* Se ha excluido la no respuesta de la base de los porcentajes. Estos pueden no sumar cien debido a que se han seleccionado los votantes de cuatro partidos o coaliciones. ** El número de casos está integrado sólo por los votantes de CP, PRD, CDS, PSOE, IU y MUC en cada una de las posiciones de la escala ideológica.

Fuente: Banco de Datos del CIS.

la extrema derecha hasta el centro se había mostrado definitivamente inviable.

Aunque los electores determinaron con sus preferencias una notable continuidad entre 1982 y 1986, las élites conservadoras concedieron a los últimos resultados una interpretación en clave negativa que habría de alterar el panorama de las fuerzas políticas. Si hemos calificado el relativo éxito de AP-PDP en 1982 como un «sub-triunfo», su situación tras 1986 puede quizás ser gráficamente descrita aplicando, servata distantia, el neologismo económico de «stagflation». La combinación del «estancamiento» electoral con la previa «inflación» de expectativas sobre su eventual triunfo generó sendos procesos de crisis internas en la Coalición y en la propia AP. El PDP y el PL, los dos partidos menores, rompieron el pacto de la Coalición y dejaron reducida la representación parlamentaria de AP a poco más de seis docenas de diputados. Aunque AP seguía siendo la segunda fuerza política de una Cámara Baja muy fragmentada, el aumento de la distancia en escaños con respecto al PSOE dificultaba sus tareas parlamentarias de oposición y redundaba negativamente en sus intentos por aparecer como alternativa al gobierno socialista 9 .

9 Cuando se escriben estas líneas, en abril de 1987, el PDP y el PL dicen pretender 
Además, AP vivió durante los últimos meses de 1986 una sucesión de conflictos internos tan graves como aparentemente interminables (De la Cierva, 1987). AP hubo de afrontar una situación económica próxima a la bancarrota como consecuencia de las deudas contraídas durante la última campaña electoral. Las tensiones intrapartidistas generaron la dimisión de numerosos líderes secundarios y la expulsión de un sector de sus líderes nacionales, incluyendo a cuatro parlamentarios. Y, sobre todo, las continuas maniobras para sustituir a Fraga en la dirección de AP coadyuvaron a que aquél presentara, en diciembre de 1986, su dimisión: las luchas faccionales desatadas en AP y la falta de apoyos de los representantes de sectores sociales a los que Fraga creía, y quería, representar precipitaron su decisión. La crisis de AP patentizó dos de los denominados «vicios» tradicionales de la derecha española. De un lado, la importante presencia de los factores personalistas en los conflictos internos, que se traducía en una deficiente institucionalización del partido y en una excesiva dependencia del líder carismático. De otro, la relativa falta de autonomía de sus proyectos políticos, cuyas vinculaciones con organizaciones sociales o económicas facilitaban el intervencionismo de éstas en los procesos de adopción de decisiones del partido conservador y vinculaban su imagen con la defensa de intereses particulares. Como ha escrito Arias Salgado (1986: 15), el síndrome de la «incapacidad organizativa de la derecha», puesto de manifiesto por la dimisión de Fraga, incluiría factores como el

«exceso de personalismo; incompatibilidad entre el yo y el partido cuando el partido no promociona el yo, lo que se traduce en el rechazo de la decisión mayoritaria adoptada en contra del propio criterio; apelación a la conciencia como coartada de la indisciplina; escasa propensión al trabajo desinteresado; intensa inclinación hacia la conspiración palaciega extremadamente dañina; impulso irrefrenable de figuración pública; inhabilidad para plantear y conducir la inevitable lucha por el poder sin franquear los límites que conducen a la autodestrucción, y, por último, en el caso de algunos líderes y dirigentes, una concepción patrimonialista del partido como si éste fuera de su propiedad privada».

Tras diez años personificando AP, la dimisión de Fraga cerraba una época ya histórica de política conservadora. Suponía también una excelente oportunidad para asentar la nueva fase de AP sobre bases más sólidas de las que hasta ahora han predominado. Los comienzos de la nueva fase, sin embargo, no han parecido caminar por esa dirección. El proceso de sustitución de Fraga se realizó en un enrarecido ambiente de enfrentamientos personalistas, en el que las estrategias de renovación ideológica y partidista terminaron brillando

competir con el PSOE por los votos del centro, por sí mismos o integrados en una nueva coalición centrista, unos objetivos que probablemente excedan de sus escasas posibilidades políticas y electorales. 
por su ausencia: La discusión sobre el futuro de AP no pasó de las operaciones personales e intrigas internas destinadas a recabar apoyos para los candidatos a la sucesión de Fraga. Como lo expresaba uno de ellos, el panorama de la derecha española era «alucinante»; y su situación, un «pleno caos desintegrador» ${ }^{10}$. En el Congreso extraordinario, celebrado en febrero de 1987, resultó elegido nuevo presidente Antonio Hernández Mancha, un joven y populista senador sin más experiencia política que la de presidir el partido en Andalucía. Su llegada suscita más incógnitas de las que resuelve. A la vista de sus primeras declaraciones (definiendo a AP como una «derecha moderna y europea», señalando los límites del partido «hasta la frontera del PSOE, sin dejar ningún hueco en el medio» y haciendo de las próximas elecciones una prueba de fuerza del nuevo liderazgo) ${ }^{11}$, parecen resucitarse tendencias ya clásicas en etapas anteriores de la evolución de AP; unas tendencias consagradas por su notable contribución a la generación de expectativas infundadas y a resultados próximos al fracaso. Con este bagaje, AP, que con sus 222.000 afiliados declarados decía ser el primer partido español (Fraga Iribarne, 1986: 156), comenzaba una nueva andadura de inciertos logros. Es dudoso que los cambios llevados a cabo tras su crisis postelectoral sean por sí mismos suficientes para lograr la recomposición de la derecha; es, incluso, improbable que esos cambios sean todos los necesarios a fin de encarnar esa nueva derecha que pretendían algunos de sus líderes. Los acontecimientos políticos y electorales de los próximos años, a los que los dirigentes aliancistas gustan de remitir la prueba de sus intenciones, nos permitirán comprobar la realización efectiva de aquellos supuestos o, por el contrario, la continuidad de situaciones caracterizadas por el eadem, sed aliter del filósofo. Lo único que parece cierto es que, tras diez años de competición partidista democrática, la articulación política de la derecha seguía siendo un problema irresuelto. La última parte de este trabajo analizará brevemente, desde la óptica limitada de $\mathrm{AP}$, algunos de los factores relacionados con ese problema.

\section{La debilidad de la derecba española: las imágenes y las posiciones} ideológicas de AP

La debilidad de la derecha tiene fuertes raíces en la historia política española. Sin necesidad de remontarse hasta el siglo xIx, basta recordar las características estructurales de los partidos conservadores durante la segunda fase de la Restauración, la tardía implantación del modelo de partido de masas en el campo de la derecha, su acusada proclividad a soluciones políticas excep-

${ }_{10}$ Declaraciones de Antonio Hernández Mancha, recogidas en El País, 30 enero 1987, p. 13.

${ }_{11}$ Declaraciones de Antonio Hernández Mancha, recogidas en El País, 8 y 9 febrero 1987, pp. 11 y 13, respectivamente. 
cionales, la participación activa de sus principales líderes en la institucionalización y consolidación de la dictadura (Rodríguez Aramberri, 1980; Santamaría, 1984). El franquismo ha sido, incluso, considerado interpretable en buena parte desde el punto de vista de la debilidad organizativa democrática de la derecha (Maravall, 1984). Como en 1931, los inicios de la transición democrática sorprendieron al campo conservador en una llamativa situación de inarticulación política y de confusión organizativa. Tras no pocas décadas en las que la gestión política de sus intereses se llevó a cabo al margen de los partidos por ser innecesarios o hallarse prohibidos, el espectro conservador se veía nuevamente obligado a afrontar su debilidad organizativa.

No es del todo extraño que, con esos antecedentes, el término de la primera década democrática no arroje resultados demasiado brillantes. Es cierto que UCD consiguió superar el vacío organizativo de la derecha y obtener éxitos relativos de importancia en dos elecciones sucesivas; pero, como es notorio, sin excesiva continuidad. También lo es que AP logró abandonar la posición subordinada con respecto a UCD y conocer a costa de ella un extraordinario crecimiento electoral; pero ya se ha comprobado, sin embargo, que ese crecimiento, además de ser insuficiente en el nuevo sistema de partidos de 1982, se transformó algún tiempo después en un estancamiento electoral de improbable remoción. La desintegración de UCD y las sucesivas crisis de Coalición Popular y de la propia AP volvieron a poner de manifiesto la notable capacidad de autodestrucción de las organizaciones conservadoras, así como la inadecuación de los valores de sus principales líderes ante las exigencias de eficacia de la competición partidista democrática. Los supuestos estratégicos que hicieron fortuna en la destrucción de UCD se han revelado absolutamente insuficientes para constituir una alternativa válida al PSOE. Como en las anteriores ocasiones históricas en las que fueron desalojados del gobierno, sus intentos por recuperarlo nuevamente han reiterado los errores de una planificación a muy corto plazo, y que se basaba, por lo demás, en definiciones deformadas de la situación. Las críticas de los propios conservadores a la «desunión de la derecha», y sus aspiraciones a que un solo partido de la «derecha política» represente a esa supuesta «derecha sociológica» mayoritaria en España, gozan también de ecos históricos (Calero, 1985; De la Cierva, 1987; Fraga Iribarne, 1986).

Pero, ahora como entonces, no parece que la fragmentación conservadora tenga visos de eliminarse, ni que, de otra parte, sus percepciones sobre la configuración ideológica de la sociedad española abandonen los prejuicios que no pueden sino originar planteamientos erróneos. Los resultados obtenidos por $\mathrm{AP}$ en los intentos de restringir a un solo partido la alternativa al PSOE o de situar en la derecha el ámbito de la competencia electoral e ideológica serían ejemplos significativos. Otras consecuencias son igualmente importantes. Desde el punto de vista territorial, la distribución del voto conservador resulta notablemente desigual. Los perfiles sociales de su electorado dificultan 
la consideración interclasista de AP como un partido de naturaleza catb-all (Montero, 1987). En términos comparativos con los partidos conservadores europeos, AP es uno de los que exhiben menor fuerza electoral en contextos de fragmentación partidista relativamente baja, sobre todo en su propio campo ideológico (Von Beyme, 1986). La intensidad de los sentimientos negativos que suscita dificulta, además, su capacidad coalicional con los partidos de centro, a los que AP considera, no obstante, «afines», y especialmente con los nacionalistas vascos o catalanes (Linz, $1986 a$; Linz et al., 1986). Y las posiciones ideológicas y las imágenes de AP, que según sus líderes la hacen formar parte de la nueva derecha (Fraga, 1981: 235), le alejan, sin embargo, de las tendencias neoconservadoras que están experimentando sus correligionarios europeos (Girvin, 1987; Dubiel, 1985).

¿Cómo se han manifestado esas posiciones e imágenes aliancistas en la primera década democrática? El hecho de que la transición se efectuara a mediados de los años setenta no dejó de incidir en la configuración de la debilidad de la derecha. Para empezar, el proyecto conservador español no podía afirmarse, como el de otros países europeos, sobre una gestión anterior socialdemócrata y un Estado de bienestar desarrollado, sino que debía reconocer forzosamente el punto de partida de la dictadura (Montoro, 1987; Laporta, 1986). Además, la coyuntura histórica de la transición española privó a la derecha de una serie de temas y posiciones que le favorecieron en otras democracias europeas ( $\mathrm{Linz}, 1986$ a). La ausencia de una izquierda revolucionaria y la escasa fuerza del PCE impidieron que la bandera del anticomunismo movilizara al electorado conservador. La creciente secularización de la sociedad privó a la derecha de otra de sus clásicas bases potenciales de movilización, permitiendo incluso que el PSOE obtuviera el voto de muchos católicos practicantes (Linz, $1986 b$; Montero, $1986 a$; Pérez Díaz, 1987). Y, en el plano internacional, el europeísmo y el difuso antiamericanismo de los partidos relevantes dificultaron que la derecha se beneficiara, en medida similar a la de sus correligionarios europeos, de las opciones occidentales y atlantistas. Resulta, así, que

«la coyuntura histórica, menos favorable a la derecha española que a la de otros países, (...) hacía necesario para su éxito un programa de integración modernizador y secularizado, que no amenazara el welfare state, sino que lo racionalizara, que captara a las nuevas y viejas clases medias y al empresario medio y que captara, asimismo, las ilusiones generadas por la transición pacífica y consensual a la democracia. La UCD parecía encarnar esa derecha, y la encarnó, efectivamente, para muchos de sus votantes; pero esa posibilidad (...) se frustró, aunque no a causa de su electorado» (Linz, 1986 a: 650).

AP compartió con UCD aquellas carencias, pero conoció, además, dificultades específicas que incidirían de forma negativa en sus planes de expansión, 
sobre todo a partir de 1982, cuando suplantó parcialmente al partido centrista. Esas dificultades cristalizaron en las imágenes neofranquistas de AP durante la fase inicial de la transición y, una vez amortiguada su intensidad, en las percepciones de AP como un partido derechista (en sentido peyorativo) antes que conservador. Si las primeras ocasionaron un déficit de legitimidad democrática en $\mathrm{AP}$ que sólo con el paso del tiempo pudo superarse, al menos en una gran parte, las segundas contribuyeron a su alejamiento del centro de gravedad ideológico del electorado, imposibilitando así su consideración como una alternativa válida al PSOE.

La transición política propició también la fundamentación de esas dificultades, y las imágenes fletadas por AP hicieron el resto. El restablecimiento de la democracia conllevó en España, como en muchos otros países europeos, el descrédito general de cuantos objetos y líderes políticos, así como etiquetas ideológicas, hubieran tenido papeles relevantes en el pasado autoritario. Los procesos de deslegitimación de todo lo que pudiera identificarse con ese pasado antidemocrático fueron especialmente intensos en el caso español. La larga duración de la dictadura; su contenido hiperconservador, cuando no reaccionario; la visibilidad de las élites políticas conservadoras, y su protagonismo en el bando vencedor de la guerra civil potenciaron la equiparación entre el franquismo y las derechas, entre conservadurismo y autoritarismo. Numerosos estudios han comprobado desde diferentes ángulos la virtualidad de esa identificación, que no podía por menos que hipotecar la capacidad de maniobra de las fuerzas tildadas, por sí mismas o por las demás, de derechistas o conservadoras en la nueva etapa democrática (Jiménez Blanco et al., 1977; Maravall, 1984; Montero, 1987; Sani y Montero, 1986). Todavía en 1984, por ejemplo, los significados atribuidos al término derecha primaban las posiciones particularistas de clase o las facetas ideológicas de difícil compatibilización con el sistema democrático. Cerca de la mitad de los entrevistados con opinión al respecto señalaba para la izquierda la «defensa de los intereses de clase», mientras que la mitad apuntaba para la derecha la «defensa de los privilegios de la clase alta»; y una cuarta parte definía a la izquierda en términos de «progresismo», «libertad» e «idealismo no práctico», mientras que cerca de otra mitad caracterizaba a la derecha con los de «autoritarismo», «conservadurismo», «orden» y «religiosidad» (CIS, 1984 b). El fenómeno general de la superioridad política del término izquierda se combinaba, así, con los contenidos históricamente negativos asociados con el de la derecha (Laponce, 1981).

Los dos principales partidos conservadores españoles obtuvieron resultados desiguales en su confrontación con esa supervivencia cultural de la reciente dictadura. UCD logró un notable éxito al intentar la desvinculación de su imagen de los contenidos asociados con el franquismo; el énfasis concedido a su centrismo, su contribución a la implantación del nuevo sistema democrático y su protagonismo gubernamental en la adopción de políticas reformistas 
lo permitieron finalmente. AP, en cambio, se movió volis nolis en la dirección contraria, facilitando su conversión en el máximo representante partidista de las identificaciones entre derechismo/conservadurismo y franquismo/autoritarismo. Como ya se apuntó con anterioridad, la imagen de la AP de 1977 era fundamentalmente «franquista» (véase supra, tabla 2). En ella coincidían tanto el electorado en general como los propios votantes conservadores, que asumían con orgullo un pasado para ellos positivo (Linz et al., 1981). Con el paso del tiempo y el incremento electoral de AP, estas apreciaciones se amortiguaron un tanto, pero no demasiado: la valoración positiva de la dictadura, los sentimientos positivos hacia Franco y la identificación con el término tranquismo siguieron siendo muy superiores entre los votantes de AP (Montero, 1986 b y 1987). No resulta, por lo tanto, extraño que en 1985 sectores considerables del electorado percibiesen a AP como un partido «autoritario» en mucha mayor medida que «democrático», como «caciquil» antes que «capacitado para gobernar bien», como «pasado de moda» más que «moderno», en unas imágenes que se invertían completamente para el caso del PSOE (tabla 6). Y tampoco lo es que esas imágenes negativas se vieran frecuentemente corroboradas por las manifestaciones de los votantes aliancistas sobre la legalidad y eficacia del sistema democrático español, así como sobre el Estado de las Autonomías, cuyas actitudes y opiniones positivas al respecto se han mantenido siempre por debajo de las del electorado y las de los restantes partidos nacionales. Por citar algún dato global significativo, sólo la mitad de los votantes potenciales de AP en 1985 opinaba que «la democracia es preferible a cualquier forma de gobierno», mientras que una cuarta parte señalaba que, «en algunas circunstancias, un régimen autoritario, una dictadura, puede ser preferible a un sistema democrático»" ${ }^{12}$.

Con todo, las dificultades de AP no residían sólo en la continuada vigencia de estas imágenes. Aunque ciertamente necesarias para impedir su expansión electoral, puede ocurrir que no sean suficientes para ciertos sectores de votantes. $\mathrm{Y}$ es que, además de aquéllas, la debilidad de AP radica sobre todo en la naturaleza excesivamente conservadora de sus propuestas, lo que ha originado su percepción como un partido fundamentalmente derechista y, en consecuencia, su acusada distancia ideológica de la mayor parte del electorado español. En algunos casos, autoritarismo y conservadurismo integraron conjuntamente la imagen de AP, como si se trataran de las dos caras de una misma moneda. Así debió ocurrir en los primeros años de la transición, cuando la atribución franquista de AP era asociada sin solución de continuidad con, o incluso subsumida bajo, su condición de un partido próximo a la extrema derecha antidemocrática. En otros casos, el solapamiento de ambas imágenes ha podido dar lugar con el paso del tiempo a un cierto desdoblamiento,

12 Estos datos, así como los de la tabla 6 , proceden de la encuesta realizada por el CIS en mayo de 1985 a una muestra nacional representativa de 2.500 españoles mayores de edad. 


\section{TABLA 6}

Imágenes de AP y del PSOE según sus votantes potenciales $y$ el electorado, 1985 *

1. Imágenes de $A P$

$\begin{array}{llllllllll}\text { Democrático } & \ldots & \ldots & \ldots & \ldots & \ldots & \ldots & \ldots & \ldots & \ldots\end{array}$

$\begin{array}{llllllllllll}\text { Autoritario } & \ldots & \ldots & \ldots & \ldots & \ldots & \ldots & \ldots & \ldots & \ldots & \ldots\end{array}$

$\begin{array}{lllllllllll}\text { Honesto } & \ldots & \ldots & \ldots & \ldots & \ldots & \ldots & \ldots & \ldots & \ldots & \ldots\end{array}$

$\begin{array}{lllllllllllll}\text { Corrupto } & \ldots & \ldots & \ldots & \ldots & \ldots & \ldots & \ldots & \ldots & \ldots & \ldots\end{array}$

Capacitado para gobernar $\ldots \begin{array}{llllll} & \ldots & \ldots & \ldots & \ldots & \ldots\end{array}$

$\begin{array}{llllllllllll}\text { Caciquil } & \ldots & \ldots & \ldots & \ldots & \ldots & \ldots & \ldots & \ldots & \ldots & \ldots\end{array}$

$\begin{array}{lllllllllllll}\text { Moderno } & \ldots . & \ldots & \ldots & \ldots & \ldots & \ldots & \ldots & \ldots & \ldots & \ldots & \ldots\end{array}$

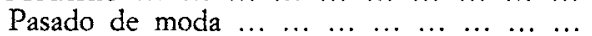

Votantes potenciales

2. Imágenes del PSOE

$\begin{array}{lllllllllll}\text { Democrático } & \ldots & \ldots & \ldots & \ldots & \ldots & \ldots & \ldots & \ldots & \ldots\end{array}$

$\begin{array}{lllllllllll}\text { Autoritario } & \ldots & \ldots & \ldots & \ldots & \ldots & \ldots & \ldots & \ldots & \ldots & \ldots\end{array}$

$\begin{array}{lllllllllll}\text { Honesto } & \ldots & \ldots & \ldots & \ldots & \ldots & \ldots & \ldots & \ldots & \ldots & \ldots\end{array}$

$\begin{array}{llllllllllll}\text { Corrupto } & \ldots & \ldots & \ldots & \ldots & \ldots & \ldots & \ldots & \ldots & \ldots & \ldots\end{array}$

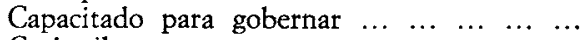

$\begin{array}{llllllllllll}\text { Caciquil } & \ldots & \ldots & \ldots & \ldots & \ldots & \ldots & \ldots & \ldots & \ldots & \ldots\end{array}$

$\begin{array}{lllllllllll}\text { Moderno } & \ldots & \ldots & \ldots & \ldots & \ldots & \ldots & \ldots & \ldots & \ldots & \ldots\end{array}$

$\begin{array}{lllllllll}\text { Pasado de } \operatorname{moda} & \ldots & \ldots & \ldots & \ldots & \ldots & \ldots & \ldots & \ldots\end{array}$

AP PSOE

Electorado

\begin{tabular}{|c|c|c|}
\hline 63 & 11 & 21 \\
\hline 31 & 75 & 65 \\
\hline 49 & 8 & 17 \\
\hline 1 & 18 & 16 \\
\hline 70 & 11 & 26 \\
\hline 5 & 51 & 40 \\
\hline 15 & 4 & 6 \\
\hline 8 & 34 & 28 \\
\hline
\end{tabular}

(n)

37
39
22
20
21
16
23
12

75
8
48
2
69
2
30
2

(292)

(809)

60

18

37

9

48

7

30

5

(2.493)

* Proporciones de respuestas a la siguiente pregunta: «En esta tarjeta que le voy a mostrar aparecen algunos juicios u opiniones sobre los partidos. Para cada uno de los partidos que le voy a indicar, quisiera que me dijese las tres opiniones que mejor responden a la imagen que usted tiene de cada uno de ellos.»

Fuente: Banco de Datos del CIS.

a una mayor autonomía relativa de cada una de ellas, pero con efectos similares: su escaso atractivo electoral no estaría ya fundamentado en su naturaleza derechista en cuanto autoritaria, o viceversa, sino en su doble condición de partido dudosamente democrático y, además, excesivamente conservador. $Y$ cabe imaginar aún a otros electores para quienes la progresiva lealtad democrática de AP no ha impedido que siga siendo una opción inaceptable de voto a causa de su conservadurismo.

Algunos datos empíricos avalan estas interpretaciones. Desde 1979, las percepciones del electorado sobre la ubicación ideológica de AP en el continuum izquierda-derecha no han experimentado cambios notables: es considerado como un partido de derechas, e incluso de la extrema derecha en mayor 
o menor medida democrática (gráfico 1 y tabla 7 ) $^{13}$. Si acaso, la principal modificación ha consistido en su mayor desplazamiento aún hacia la derecha entre 1979 y 1982, precisamente cuando AP decidió abandonar su estrategia de «centro-derecha» para adoptar la de confrontación directa con UCD primero y el PSOE después. El 21 por 100 de los votantes centristas y el 14 por 100 del conjunto del electorado que en 1979 situaban a AP en el centro se ha reducido posteriormente al 5 y 4 por 100, respectivamente, en 1986; en cambio, han aumentado las proporciones de quienes la sitúan en la derecha y, en menor medida, en la extrema derecha. No hace falta exagerar la importancia de estas apreciaciones para las estrategias de la competición interparti-

\section{GRAFICO 1}

Las ubicaciones de AP en una escala ideológica izquierda-derecba, $1979-1986 *$

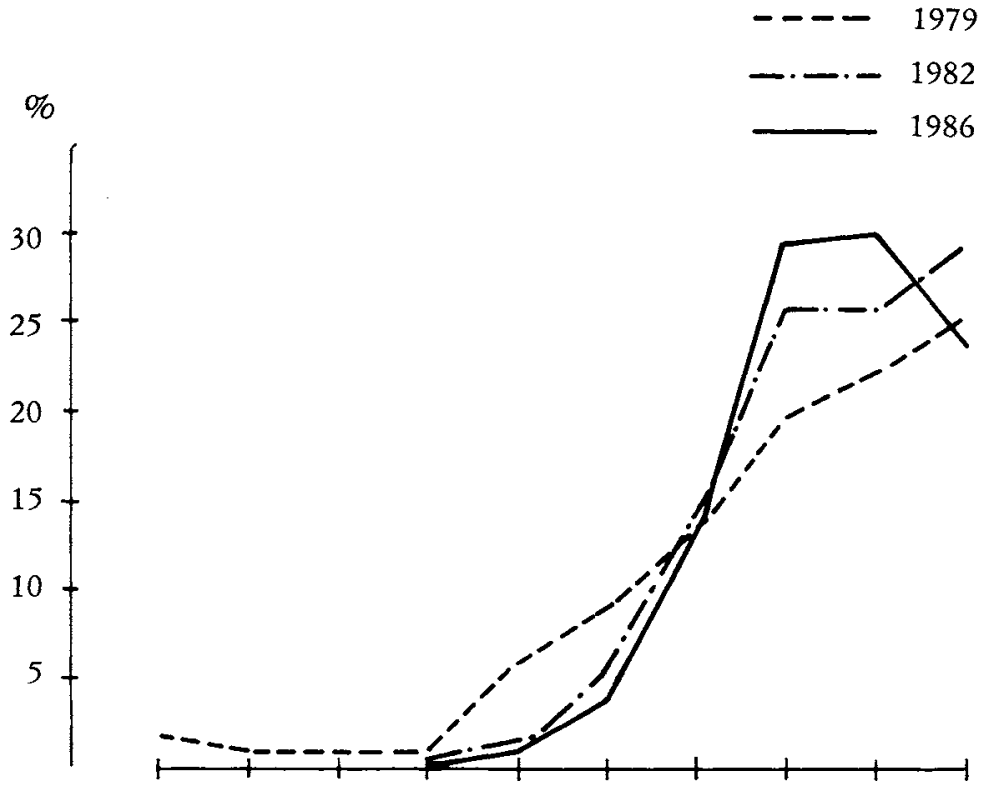

Izquierda

Derecha

* Se ha excluido la no respuesta de la base de los porcentajes. La escala es de diez puntos.

Fuentes: Para 1979 y 1982, Encuestas DATA, 1979 y 1982; para 1986, Banco de Datos del CIS.

${ }^{13}$ Los datos de la tabla 7 proceden de la encuesta citada supra, nota 8. 


\section{TABLA 7}

Las percepciones ideológicas de AP: proporciones de los votantes de partidos nacionales que conciben a AP como un partido de centro, derecha o extrema derecha, 1979-1986*

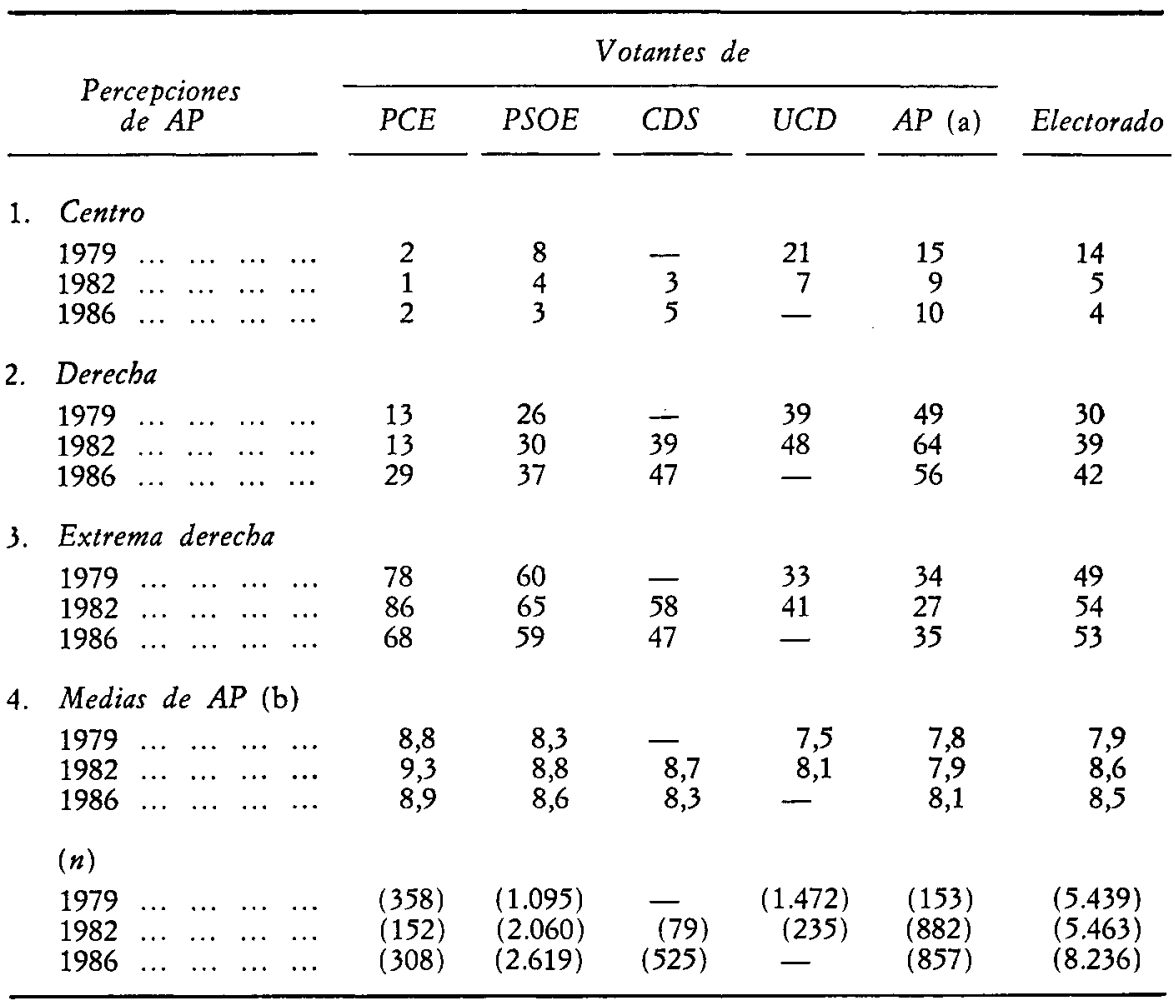

* Se ha excluido la no respuesta de la base de los porcentajes y cálculos. Las columnas correspondientes a cada año pueden no sumar cien debido a que no se han incluido los porcentajes (por lo demás, mínimos) de quienes situaban a $\mathrm{AP}$ en el centro-izquierda.

(a) En 1979, AP-CD; en 1982, AP-PDP; en 1986, CP.

(b) Posiciones medias en la escala de diez puntos.

FunNTES: Para los votantes de las elecciones legislativas de 1979 y 1982, Encuestas DATA, 1979 y 1982; para los de 1986, Banco de Datos del CIS.

dista por la mayoría del electorado; una competición en la que AP, pese a su crecimiento electoral de 1982, no parece tener por el momento demasiadas posibilidades de éxito a la vista, por ejemplo, de las percepciones sobre su creciente derechización, o de que en 1986 cerca de las dos terceras partes de los votantes del PSOE, cerca de la mitad de los del CDS y algo más de la 
mitad del electorado desplazasen a AP a las posiciones más extremas del continuo ideológico.

Como cabía esperar, estos datos muestran una estrecha relación con los referentes a la ubicación ideológica de los líderes aliancistas y de los propios votantes conservadores. En 1984, el 47 por 100 del electorado situaba a Fraga Iribarne en las posiciones de la derecha, y un 45 por 100 en los de extrema derecha; la media atribuida a Fraga en una escala ideológica de 10 puntos era la muy alejada del $8,3^{14}$. Por lo que hace a la autoubicación ideológica de los votantes conservadores, resulta interesante comprobar su progresiva derechización, paralela, en cierto modo, a las crecientes percepciones sobre el conservadurismo del partido (gráfico 2 y tabla 8 ). Pese a su derrota electoral, la

\section{GRAFICO 2}

Autoubicación de los votantes de AP ( $y$ de coaliciones con AP) en una escala ideológica izquierda-derecha, 1979-1986*

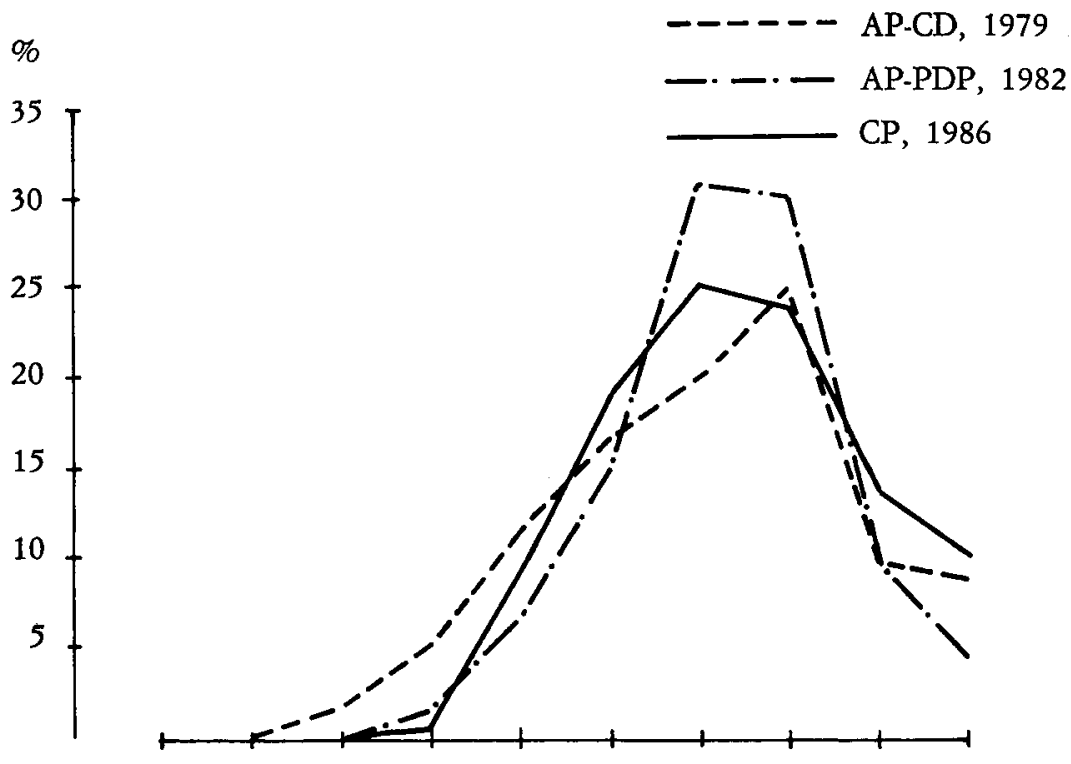

Izquierda

Derecha

* Se ha excluido la no respuesta de la base de los porcentajes. La escala es de diez puntos. FuENTEs: Para 1979 y 1982, Encuestas DATA, 1979 y 1982; para 1986, Banco de Datos del CIS.

${ }^{14}$ Según los datos de la encuesta realizada por el CIS en abril de 1984 a una muestra representativa nacional de 2.474 españoles mayores de edad. 
TABLA 8

Autoubicación ideológica de los votantes de AP

( $y$ de coaliciones con AP), 1979-1986

(En porcentajes) *

\begin{tabular}{|c|c|c|c|}
\hline $\begin{array}{l}\text { Autoubicación } \\
\text { ideológica }\end{array}$ & $\begin{array}{c}A P-C D \\
1979\end{array}$ & $\begin{array}{c}A P-P D P \\
1982\end{array}$ & $\begin{array}{l}\text { CP, } \\
1986\end{array}$ \\
\hline 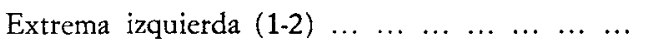 & - & - & - \\
\hline $\begin{array}{llllllllll}\text { Izquierda }(3-4) & \ldots & \ldots & \ldots & \ldots & \ldots & \ldots & \ldots & \ldots & \ldots\end{array}$ & 7 & 2 & 1 \\
\hline 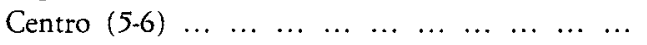 & 29 & 22 & 27 \\
\hline 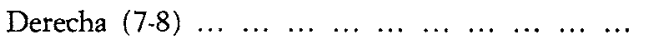 & 45 & 61 & 48 \\
\hline Extrema derecha $(9-10) \ldots \ldots c c c c c c$ & 18 & 14 & 23 \\
\hline $\begin{array}{llllllllllll}\text { Media } & \ldots & \ldots & \ldots & \ldots & \ldots & \ldots & \ldots & \ldots & \ldots & \ldots & \ldots\end{array}$ & 7,1 & 7,2 & 7,4 \\
\hline $\begin{array}{llllllllllll}(n) & \ldots & \ldots & \ldots & \ldots & \ldots & \ldots & \ldots & \ldots & \ldots & \ldots & \ldots\end{array}$ & (153) & $(857)$ & $(888)$ \\
\hline
\end{tabular}

* Se ha excluido la no respuesta de la base de los porcentajes y cálculos.

Fuentes: Para los votantes de AP-CD y de AP-PDP en las elecciones legislativas de 1979 y 1982, Encuestas DATA, 1979 y 1982; para los de CP en las de 1986, Banco de Datos del CIS.

estrategia de «centro-derecha» de AP-CD en 1979 propició el que casi una tercera parte de sus votantes se autosituara en las posiciones ideológicas del centro. Y la masiva entrada en la AP-PDP de 1982 de antiguos votantes de UCD aumentó considerablemente el espacio ideológico de la derecha, que en 1986 se ha visto reducido en beneficio de la extrema derecha. Si concedemos a las autoubicaciones de los votantes en el continuo izquierda-derecha el papel de indicadores aproximados de sus identidades políticas (Sani y Montero, 1986), es claro que las de los electores conservadores manifiestan un acusado conservadurismo, que lo es tanto más cuanto que se hallan notablemente alejados de las de los principales partidos, y sobre todo de las del conjunto de los españoles (tabla 9) ${ }^{i 5}$. Resultaba así que las percepciones sobre las posiciones ideológicas de AP no se alejaban demasiado de las que los propios votantes del partido tenían de sí mismos. Las diferencias entre unas y otras, que obedecían a la conocida pauta por la que los votantes se colocan en posiciones más «centradas» que las que otorgan a sus respectivos partidos (Maravall, 1984), no invalidan la correspondencia básica entre la etiqueta de partido de

15 Para una serie completa sobre la evolución del voto desde 1979 , y sobre la autoubicación ideológica del electorado y de los partidos relevantes desde 1983, véase CIS (1984 a y 1986). 


\section{TABLA 9}

Autoubicación ideológica de los votantes de AP ( $y$ de coaliciones con AP) de los votantes de partidos nacionales y del electorado, 1977-1986* nacionales $y$ del electorado, 1977-1986*

\begin{tabular}{|c|c|c|c|c|c|c|c|c|c|c|c|}
\hline & & & & & & \multicolumn{5}{|c|}{ Votantes de } & \multirow[b]{2}{*}{ Electorado } \\
\hline & & \multicolumn{4}{|c|}{$A \tilde{n} o s$} & PCE (a) & PSOE & $C D S$ & $U C D$ & $A P(\mathrm{~b})$ & \\
\hline 1977 & $\ldots$ & $\ldots$ & $\ldots$ & $\ldots$ & $\ldots$ & 2,7 & 3,9 & - & 5,9 & 7,0 & 5,5 \\
\hline 1978 & $\ldots$ & $\ldots$ & $\ldots$ & $\ldots$ & $\cdots$ & 3,1 & 3,9 & - & 5,7 & 7,1 & 4,7 \\
\hline 1979 & $\cdots$ & $\cdots$ & $\cdots$ & $\cdots$ & $\cdots$ & 2,7 & 3,9 & - & 5,7 & 7,1 & 4,7 \\
\hline 1980 & $\ldots$ & $\ldots$ & $\ldots$ & $\ldots$ & $\ldots$ & 2,5 & 3,6 & - & 5,6 & 7,2 & 4,5 \\
\hline 1982 & $\begin{array}{l}\cdots \\
\cdots\end{array}$ & $\cdots$ & $\begin{array}{l}\cdots \\
\cdots\end{array}$ & $\begin{array}{l}\cdots \\
\cdots\end{array}$ & $\begin{array}{l}\cdots \\
\cdots\end{array}$ & 2,3 & 3,8 & 5,4 & 5,6 & 7,2 & 4,8 \\
\hline 1983 & $\ldots$ & $\ldots$ & $\ldots$ & $\ldots$ & $\ldots$ & 2,5 & 3,7 & - & - & 7,2 & 4,5 \\
\hline 1984 & ... & $\ldots$ & $\ldots$ & $\ldots$ & $\ldots$ & 2,7 & 3,9 & 5,5 & - & 7,1 & 4,7 \\
\hline 1985 & $\ldots$ & $\ldots$ & $\ldots$ & ... & $\ldots$ & 2,8 & 4,0 & 5,3 & - & 7,4 & 4,8 \\
\hline 1986 & $\ldots$ & $\ldots$ & $\ldots$ & & $\ldots$ & 2,5 & 3,6 & 5,1 & - & 7,4 & 4,8 \\
\hline
\end{tabular}

* Posiciones medias en escalas de diez puntos. Se ha excluido la no respuesta de la base de los caílculos.

(a) En 1986, formando la coalición Izquierda Unida.

(b) En 1977, AP; en 1979, AP-CD; en 1982, AP-PDP; en 1986, CP.

Fuentes: De 1977 a 1985, Sani y Montero (1986: 182); para 1986, Banco de Datos del CIS.

derechas atribuida por el electorado a AP y la identidad ideológica de sus votantes.

Las tablas 8 y 9 revelan también el alcance del doble fracaso aliancista que ya ha sido comentado en páginas anteriores. De un lado, la continua moderación ideológica de los españoles a lo largo de la primera década democrática (que tuvo oportunidad de canalizarse en sus mayoritarias preferencias partidistas de 1977-1979 hacia la UCD y el PSOE) demostraba que, contra los análisis conservadores, el crecimiento de AP no se había debido a un desplazamiento a la derecha del electorado, sino a los cambios producidos en la oferta partidista. De otro, la persistente distancia ideológica entre el propio electorado y AP (agravada incluso por la mayor derechización de ésta) impedía, contra las previsiones conservadoras, su expansión entre los sectores moderados. AP podía, así, hegemonizar los espacios ideológicos de la derecha y de la extrema derecha, en la que se situaban proporciones minoritarias del electorado, pero quedaba excluida como competidora por los ámbitos centrales del continuo ideológico, en el que se autoubicaban, en cambio, proporciones mucho más nutridas de votantes. Es posible, en suma, que, en cuanto derecha democrática, AP haya conseguido amortiguar las imágenes que la 
vinculan con el franquismo y lograr legitimidad democrática en el sistema de partidos, pese a las imágenes de autoritarismo que todavía le acompañan. Pero es mucho más probable que, en cuanto derecba, AP haya dado lugar a unas percepciones sobre su excesivo conservadurismo que le alejan de las opciones de voto a considerar por la mayoría del electorado (que es, además, mayoritariamente centrista y moderado y se halla ligeramente inclinado a la izquierda).

Por si todo ello fuera poco, cabe finalmente destacar que AP ocupó un papel relevante en las estructuras de antagonismo político del sistema de partidos. Quiere decirse con ello que a los problemas derivados de su limitada capacidad de atracción electoral se unieron los generados por sus elevados niveles de rechazo. De esta forma, las imágenes cristalizadas en torno a AP no actuaron tanto como una especie de filtro neutro que atenuara su atractivo electoral, sino sobre todo como un incentivo negativo para su expansión y su aceptación como alternativa al PSOE. Existen también numerosos indicadores de esta nueva faceta limitativa de AP. Entre ellos, los relativos al liderazgo de Fraga son los más abundantes, dada su visibilidad política, la importancia de su identificación con un partido tan fuertemente presidencialista cómo AP y su propia personalidad. La tabla 10 sintetiza una información básica al respecto, que ha sido desarrollada en mayor amplitud en otros estudios (Linz et al., 1981; Gunther, Sani y Shabad, 1986; Sani y Shabad, 1986). Pese a la conocida intensidad de la relación entre Fraga y su electorado conservador, resulta evidente el rechazo que suscita en el conjunto de la población y entre los votantes de los partidos incluso relativamente próximos, como el CDS. Se trata, además, de un rechazo especialmente fuerte, ya que, por regla general, la mitad de los sentimientos de hostilidad recogidos en la tabla 10 se producen en las posiciones más bajas de la escala de simpatía (la 0 o la 1). El liderazgo de Fraga combinaba, así, un altísimo índice de conocimiento entre el electorado (mucho mayor, desde luego, que el existente respecto a otros líderes del partido o de la Coalición Popular) con los mayores niveles de hostilidad. Unos niveles que no descendieron apreciablemente ni siquiera cuando AP pasó de un grupo parlamentario casi marginal a convertirse en el principal partido de la oposición, y que no son muy diferentes de los obtenidos por el líder del reducido PCE. Ahora bien, el rechazo de AP no era sólo consecuencia del cosechado a través de su máximo dirigente hasta 1986. Como puede comprobarse en la tabla 11, el propio partido no recibía valoraciones sustancialmente distintas ${ }^{16}$. De nuevo, la transformación sufrida por AP entre 1979 y 1985 ha carecido de repercusiones positivas en el depósito dersus simpatías. Alrededor de dos terceras partes del electorado manifestaban sentimientos de hostilidad hacia el partido cuando era una fuerza

16 Los datos referidos a 1985 en la tabla 11 proceden de la encuesta citada supra, nota 12. Debe tenerse en cuenta que algunas de las diferencias observadas entre 1979 y 1985 pueden ser debidas al hecho de que una escala comenzara en 0 y la otra en 1. 


\section{TABLA 10}

Valoración de Manuel Fraga según los votantes de los partidos nacionales, $1979-1986 *$

Votantes de

$\overline{A P(\mathrm{a})} \mathrm{CDS}$ PSOE PCE (b) Electorado

1. Sentimientos de bostilidad ba. cia M. Fraga (c)

$\begin{array}{rrrrrrrrrrrrr}1979 & \ldots & \ldots & \ldots & \ldots & \ldots & \ldots & \ldots & 10 & & 86 & 92 & 63 \\ 1982 & \ldots & \ldots & \ldots & \ldots & \ldots & \ldots & \ldots & 4 & 62 & 75 & 92 & 52 \\ 1986 & \ldots & \ldots & \ldots & \ldots & \ldots & \ldots & \ldots & 2 & 50 & 77 & 83 & 59\end{array}$

2. Valoración media de M. Fraga

\begin{tabular}{|c|c|c|c|c|}
\hline $\begin{array}{lllllllll}\ldots & \ldots & \ldots & \ldots & \ldots & \ldots & \end{array}$ & 7,5 & - & 1,9 & 1,3 \\
\hline $\begin{array}{cc}\cdots & \cdots \\
\end{array}>>2$ & 7,7 & 3,7 & 2,7 & 1,2 \\
\hline$\ldots$ & 8,3 & 4,3 & 2,1 & 1,4 \\
\hline
\end{tabular}

3. Valoraciones medias de otros lideres políticos (1986)

\begin{tabular}{|c|c|c|c|c|c|c|}
\hline \multicolumn{2}{|c|}{$\begin{array}{lllll}\text { O. Alzaga (PDP) } & \ldots & \ldots & \ldots \\
\text { A. Suárez (CDS) } & \ldots & \ldots & \ldots & \ldots \\
\text { F. González (PSOE) } & \ldots & \ldots & \ldots \\
\text { G. Iglesias (PCE) } & \ldots & \ldots & \ldots & \ldots\end{array}$} & $\begin{array}{l}5,8 \\
5,2 \\
4,5 \\
1,6\end{array}$ & $\begin{array}{l}3,9 \\
8,2 \\
5,3 \\
2,4\end{array}$ & $\begin{array}{l}2,6 \\
4,8 \\
7,8 \\
3,3\end{array}$ & $\begin{array}{l}2,3 \\
4,4 \\
4,7 \\
6,8\end{array}$ & $\begin{array}{l}3,4 \\
5,2 \\
6,5 \\
3,0\end{array}$ \\
\hline$(n)$ & $\begin{array}{cccccc}1979 & \ldots & \ldots & \ldots & \ldots & \ldots \\
1982 & \ldots & \ldots & \ldots & \ldots & \ldots \\
1986 & \ldots & \ldots & \ldots & \ldots & \ldots\end{array}$ & $\begin{array}{l}(155) \\
(882) \\
(899)\end{array}$ & $\begin{array}{l}\overline{(79)} \\
(547)\end{array}$ & $\begin{array}{l}(1.142) \\
(2.060) \\
(2.736)\end{array}$ & $\begin{array}{l}(360) \\
(152) \\
(276)\end{array}$ & $\begin{array}{l}(5.439) \\
(5.436) \\
(6.007)\end{array}$ \\
\hline
\end{tabular}

* Se ha excluido la no respuesta de la base de los porcentajes y de los cálculos. En 1979 y 1982 se preguntaban los sentimientos hacia Fraga, valorándolos desde 0 (hostilidad máxima) a 10 (simpatía máxima). En 1986 se preguntaba qué valoración merecía su actuación política, puntuándola desde 0 (muy mala valoración) a 10 (muy buena).

(a) En 1979, AP-CD; en 1982, AP-PDP; en 1986, CP.

(b) En 1986, formando parte de IU.

(c) En porcentajes, suma de las posiciones 0 a 4 en las escalas correspondientes.

Fuentes: Para 1979 y 1982, Encuestas DATA, 1979 y 1982; para 1986, Banco de Datos del CIS.

con sólo el 6 por 100 de los votos, subordinado en el campo conservador a la superioridad de UCD y esforzándose por disminuir sus identificaciones con la dictadura; pero otras tantas partes le siguen caracterizando de modo hostil seis años después pese a ser el segundo partido o coalición más votado, liderar la oposición al gobierno socialista e intentar la construcción de una alternativa al PSOE. Con una media de 3,8 en una escala de 10 puntos, la escasa simpatía 


\section{TABLA 11}

Sentimientos de simpatia y bostilidad bacia AP según los votantes de los partidos nacionales, 1979 y 1985 * nacionales, 1979 y $1985 *$

1. Sentimientos de simpatia bacia AP (b) $\begin{array}{llllll}1979 & \ldots & \ldots & \ldots & \ldots & 1\end{array}$ $\begin{array}{llllll}1985 & \ldots & \ldots & \ldots & \ldots & 4\end{array}$

$\begin{array}{llll}4 & - & 26 & 79 \\ 8 & 29 & - & 77\end{array}$

16

23

2. Sentimientos de bos-

tilidad hacia AP (c)

$\begin{array}{lllll}1979 & \ldots & \ldots & \ldots & \ldots\end{array}$

1985

$\begin{array}{lllll}\ldots & \ldots & \ldots & \ldots & 96 \\ \ldots & \ldots & \ldots & \ldots & 90\end{array}$

84
78

$\overline{48}$

45

13

9

65

61

3. Simpatia media bacia $A P$

$\begin{array}{lllllllllll}1979 & \ldots & \ldots & \ldots & \ldots & 0,7 & 1,8 & - & 4,2 & 7,2 & 2,9 \\ 1985 & \ldots & \ldots & \ldots & \ldots & 1,9 & 2,8 & 4,5 & - & 7,4 & 3,8\end{array}$

4. Simpatía media bacia otros partidos (1985)

CDS $\quad \ldots \quad \ldots \quad \ldots \quad \ldots$

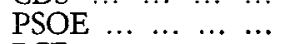

4,5

7,3

\section{4,1}

6,7

3,8

$\begin{array}{ll}6,8 & - \\ 4,7 & - \\ 2,6 & -\end{array}$

4,2
3,4
1,8

4,6

5,4

3,4

(n) $\begin{array}{llll}1979 & \ldots & \ldots \\ & 1985 & \ldots & \ldots\end{array}$

(84)

(809)

* Se ha excluido la no respuesta en la base de los porcentajes y de los cálculos. En 1979 se preguntaban los «sentimientos» hacia Coalición Democrática entre los votantes de los distintos partidos, escalonándolos desde 0 (hostilidad máxima) hasta 10 (simpatía máxima). En 1985 se preguntaba la «simpatía» hacia AP entre los votantes potenciales de los partidos, escalonándola entre 1 (ninguna simpatía) y 10 (mucha simpatía).

(a) En 1979, AP-CD; en 1985, AP-PDP.

(b) En porcentajes, suma de las posiciones 6 a 10 de ambas escalas.

(c) En porcentajes, suma de las posiciones 0 a 4 , y 1 a 4 , de las respectivas escalas.

Fuentes: Para 1979, Encuesta DATA, 1979; para 1985, Banco de Datos del CIS. 
recogida en 1985 entre el electorado resultaba, asi, cualitativamente distinta y, como es obvio, de mucha mayor importancia.

De ahí, finalmente, la continuidad de la posición (negativamente) privilegiada de AP en la exclusión de las preferencias electorales de los españoles. Cabría denominar a esta actitud como «preferencia negativa de partido»: por medio de ella, el electorado concreta sus sentimientos negativos hacia determinados partidos hasta excluirlos de sus opciones posibles de voto (tabla 12) (Sani, 1981; Sani y Shabad, 1986). El hecho de que en 1985 más de la mitad del electorado «vete» a AP, considerándola una alternativa inaceptable, y que lo haga en proporciones muy superiores a las de 1982, condensa significativamente los altos niveles de rechazo generados, entre otras razones, por su excesivo conservadurismo y su deficiente marca democrática. Condensa, en definitiva, la debilidad de la derecha española, su carencia de imagen para hacerse con esa «mayoría natural» tan larga como erróneamente perseguida, su falta

\section{TABLA 12}

«Preferencia negativa de partido», 1979-1985*

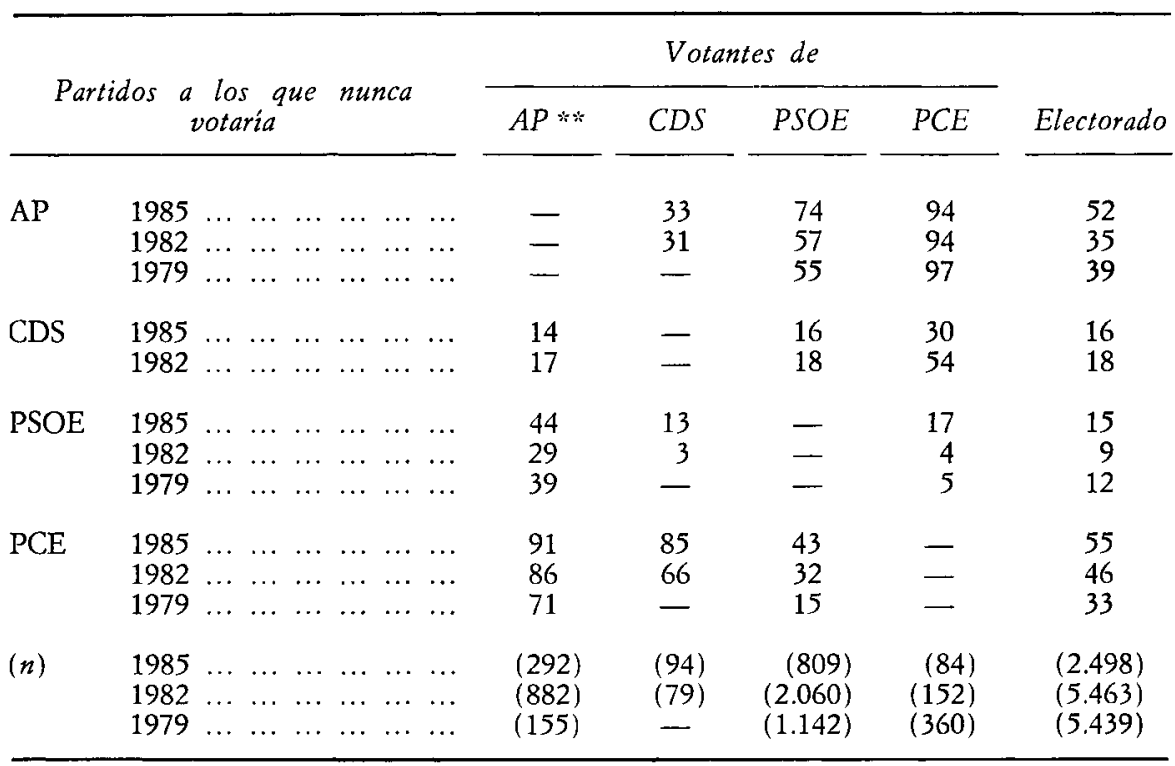

* Porcentajes de votantes (en 1985 , de votantes potenciales) que declaran que no vorarían nunca a los partidos citados.

* En 1979, AP-CD; en 1982, AP-PDP; en 1985, CP.

Fuentes: Para 1979 y 1982, Encuestas DATA, 1979 y 1982; para 1985, Banco de Datos del CIS. 
de credibilidad para lograr la alternancia en el gobierno desde unas premisas de derechas tan insistente como erráticamente defendidas. Tenía razón Schumann cuando señalaba, al principio de este artículo, que los partidos conservadores (al menos los españoles) «resisten, pero no triunfan». A diferencia de UCD, AP ha logrado, en efecto, resistir durante la primera década democrática, bien que a través de un accidentado proceso de crisis organizativas y de liderazgo, de fracasos políticos y electorales. Pero sus triunfos, a diferencia también de UCD, no se han producido todavía; o, si como tales pueden considerarse las etapas de su propia evolución partidista, distan mucho de los que la misma AP se fijó como metas. Y no parece previsible, sic rebus stantibus, que esta situación de «resistir sin ganar» vaya a invertirse bruscamente en el futuro inmediato. Los procesos de articulación política de la derecha española no han finalizado aún. De modo similar, la transformación de los partidos conservadores españoles, en la línea de ese neoconservadurismo que parece haberse instalado en la mayor parte de sus correligionarios europeos, está todavía por realizarse.

\section{REFERENCIAS}

Arias Salgado, R. (1986): «Los errores de la derecha», El País, 21 octubre: 14-15.

BAR, A. (1985): "¿Normalidad o excepcionalidad? Para una tipología del sistema de partidos español, 1977-1982», Sistema, 65: 3-37.

Buse, M. (1984): La nueva democracia española. Sistema de partidos y orientación de voto (1976-1983), Madrid: Unión Editorial.

CaCiagli, M. (1986): Elecciones y partidos en la transición española, Madrid: Centro de Investigaciones Sociológicas/Siglo XXI.

Calero, J. R. (1985): La construcción de la derecha española, Murcia: Prócer.

CENTRo DE INVESTIGACIONES SociológiCas (1984 a): «La evolución del voto: 1979-1982», Revista Española de Investigaciones Sociológrcas, 28: 305-321.

- (1984 b): «Encuesta sobre la imagen del sistema de partidos políticos», REVISTA EspaÑOLA DE INVESTIGACIONES SOCrológicAS, 28: 323-343.

- (1986): «La evolución de la intención de voto y otros indicadores políticos: 19831986», Revista Española de InVestigaciones Sociológicas, 35: 269-340.

De Esteban, J., y López Guerra, L. (1982): Los partidos políticos en la España actual, Madrid: Planeta/Instituto de Estudios Económicos.

De la Cierva, R. (1987): La derecba sin remedio (1801-1987). De la prisión de Jovellanos al martirio de Fraga, Barcelona: Plaza y Janés.

Del Aguila, R., y Montoro, R. (1984): El discurso político de la transición española, Madrid: Centro de Investigaciones Sociológicas.

Del Castillo, P., y Sani, G. (1986): «Las elecciones de 1986: Continuidad sin consolidación», en J. J. Linz y J. R. Montero (eds.): Crisis y cambio: Electores y partidos en la España de los años ocbenta, Madrid: Centro de Estudios Constitucionales, pp. $635-643$.

Dí́ż Nicolás, J. (1986): «Análisis y consecuencias de las elecciones generales de 1986», Cuenta y Razón, 25: 75-84.

Dubiel, M. (1985): Was ist Neokonservatismus?, Frankfort: Suhrkamp.

Duverger, M. (1965): Los partidos politicos, México: Fondo de Cultura Económica.

El País (1987): Anuario 1987, Madrid: Ediciones El País. 
Equip de Sociologia Electoral (1986): «El Referéndum de marzo de 1986 sobre la permanencia de España en la OTAN y sus consecuencias para el sistema político», Revista de Estudios Politicos, 52: 183-215.

- (1987): Les eleccions al Parlament de Catalunya, Barcelona: Fundació Jaume Bofill.

Espín, E. (1979): «Las fuerzas políticas concurrentes», en J. de Esteban y L. López Guerra (eds.): Las elecciones legislativas del 1 de marzo de 1979, Madrid: Centro de Investigaciones Sociológicas, pp. 65-93.

Fraga Iribarne, M. (1977): Alianza Popular, Bilbao: Albia.

- (1981): El pensamiento conservador español, Madrid: Planeta.

- (1982): El cañón giratorio. Conversaciones con Eduardo Chamorro, Barcelona: ArgosVergara.

- (1983): La leal oposición, Barcelona: Planeta.

- (1986): España bloqueada, Barcelona: Planeta.

García Morillo, J. (1979): «El desarrollo de la campaña», en J. de Esteban y L. López Guerra (eds.): Las elecciones legislativas del 1 de marzo de 1979, Madrid: Centro de Investigaciones Sociológicas, pp. 189-289.

Girvin, B. (ed.) (1987): The transformation of contemporary conservatism, Londres: Sage.

GUNT HER, R. (1986 a): «El realineamiento del sistema de partidos de 1982», en J. J. Linz y J. R. Montero (eds.): Crisis y cambio: Electores y partidos en la España de los años ochenta, Madrid: Centro de Estudios Constitucionales, pp. 27-69.

- (1986 b): «El hundimiento de UCD», en J. J. Linz y J. R. Montero (eds.): Crisis y cambio: Electores y partidos en la España de los años ochenta, Madrid: Centro de Estudios Constitucionales, pp. 433-492.

Gunt her, R.; SANI, G., y S HABAD, G. (1986): El sistema de partidos politicos en España. Génesis y evolución, Madrid: Centro de Investigaciones Sociológicas/Siglo XXI.

Hunneus, C. (1985): La Unión de Centro Democrático y la transición a la democracia en España, Madrid: Centro de Investigaciones Sociológicas/Siglo XXI.

Jiménez Blanco, J.; García Ferrando, J. M.; López Aranguren, E., y Beltrán Villalva, M. (1979): La conciencia regional en España, Madrid: Centro de Investigaciones Sociológicas.

LAPORTa, F. J. (1989): «El ignorado paradero de la derecha», El Pais, 25 octubre: 10-11.

LAPONCE, J. A. (1981): Left and right: The topography of political perceptions, Toronto: University of Toronto Press.

LARAÑA, E. (1986): «Interpretación de los resultados electorales y predicciones políticas. Las elecciones autonómicas de Andalucía y Galicia (1982 y 1985)», Revista de Estudios Políticos, 50: 285-309.

Layton-Henry, Z. (1982): "Conservatism and conservative politics», en Z. LaytonHenry (ed.): Conservative politics in western Europe, Londres: Macmillan, pp. 1-20.

Leguina, J. (1986): «La evolución del voto: 1982 y 1986. España y Madrid», Sistema, 75: 113-125.

Linz, J. J. (1980): «The new spanish party system», en R. Rose (ed.): Electoral participation: A comparative analysis, Londres: Sage, pp. 101-189.

- (1986 a): «Consideraciones finales», en J. J. Linz y J. R. Montero (eds.): Crisis y cambio: Electores y partidos en la España de los años ochenta, Madrid: Centro de Estudios Constitucionales, pp. 645-662.

- (1986 b): «Religión y política», en J. J. Linz y J. R. Montero (eds.): Crisis y cambio: Electores y partidos en la España de los años ocbenta, Madrid: Centro de Estudios Constitucionales, pp. 201-256.

Linz, J. J.; Gómez-Reino, M.; Orizo, F. A., y Vila, D. (1981): Informe sociológico sobre el cambio politico en España, 1975-1981, Madrid: Eutoamérica.

- (1986): Conflicto en Euskadi, Madrid: Espasa-Calpe.

Linz, J. J., y Montero, J. R. (eds.) (1986): Crisis y cambio: Electores y partidos en la España de los años ocbenta, Madrid: Centro de Estudios Constitucionales.

López Nieto, L. (1985): Alianza Popular. Aproximación al estudio científico-político de un partido conservador (tesis doctoral), Madrid: Universidad Complutense.

López Pintor, R. (1982): La opinión pública española del franquismo a la democracia, Madrid: Centro de Investigaciones Sociológicas.

- (1985): «Francoist reformers in democratic Spain: The Popular Alliance and the Democratic Coalition», en H. R. Penniman y E. M. Mujal-León (eds.): Spain at the 
polls, 1977, 1979, and 1982. A study of the national elections, Washington, D. C.: American Enterprise Institute, pp. 188-205.

López Pintor, R., y Justel, M. (1982): «Iniciando el análisis de las elecciones generales de 1982 (Informe de un sondeo postelectoral)», Revista Española DE Investigaciones SOCIOLÓGICAS, 20: 155-168.

Llera Ramo, F. (1985): «El sistema de partidos en la Comunidad Autónoma del País Vasco», Revista de Estudios Políticos, 46-47: 527-552.

Maravall, J. M. ${ }^{2}$ (1984): La política de la transición, Madrid: Taurus.

Maravall, J. M.a, y Santamaría, J. (1985): "Crisis del franquismo, transición política y consolidación de la democracia en España», Sistema, 68-69: 79-129.

Martínez, R. E. (1984): Business elites in democratic Spain (tesis doctoral), New Haven: Yale University.

Montero, J. R. (1984): «Niveles, fluctuaciones y tendencias del abstencionismo electoral en España y Europa», Revista Española de Investigaciones Sociológicas, 28: 223-242.

- $(1986 a)$ : «La vuelta a las urnas: Participación, movilización y abstención», en J. J. Linz y J. R. Montero (eds.): Crisis y cambio: Electores y partidos en la España de los años ochenta, Madrid: Centro de Estudios Constitucionales, pp. 71-124.

- (1986 b): «El sub-triunfo de la derecha: Los apoyos electorales de AP-PDP», en J. J. Linz y J. R. Montero (eds.): Crisis y cambio: Electores y partidos en la España de los años ochenta, Madrid: Centro de Estudios Constitucionales, pp. 344-432.

- $(1986 c)$ : «Iglesia, secularización y comportamiento político en España», Revista EsPAÑola de InVESTIgACIONES Sociológicas, 34: 131-159.

- (1987): «Alianza Popular, Coalición Democrática y Coalición Popular (1976-1986): La evolución de la derecha española en la primera década democrática», en J. Santamaría (ed.): Los partidos políticos españoles, Madrid: Centro de Investigaciones Sociológicas.

Montoro, R. (1987): «Neoconservadurismo y crisis del Estado de bienestar», en Politica y sociedad. Estudios en bomenaje a Francisco Murillo Ferrol, Madrid: Centro de Investigaciones Sociológicas/Centro de Estudios Constitucionales, pp. 268-283.

Muñoz Alonso, A., et al. (1984): Las elecciones del cambio, Barcelona: Argos-Vergara.

PAyne, S. G. (1986): «The parliamentary elections of june 1986», en S. G. Payne (ed.): The politics of democratic Spain, Chicago: Chicago Council on Foreign Relations, pp. 246-255.

PÉrez Díaz, V. (1987): El retorno de la sociedad civil, Madrid: Instituto de Estudios Económicos.

Porras, A. (1985): Geografía electoral de Andalucía, Madrid: Centro de Investigaciones Sociológicás/Siglo XXI.

Portero, J. A.; Blanco, R., y Maiz, R. (1982): Las elecciones en Galicia. Elecciones al Parlamento, La Coruña: Ediciones Nos.

Pu H LE, H.-J. (1986): «El PSOE: Un partido predominante y heterogéneo», en J. J. Linz y J. R. Montero (eds.): Crisis y cambio: Electores y partidos en la España de los años ocbenta, Madrid: Centro de Estudios Constitucionales, pp. 289-344.

Robinson, R. (1987): «From change to continuity: The 1986 spanish election», West European Politics, 10: 121-124.

Rodríguez Aramberri, J. (1980): «Origen y evolución del sistema de partidos en la España democrática: Un ensayo de interpretación», en F. Claudín (ed.): ¿Crisis de los partidos políticos?, Madrid: Dédalo, pp. 65-152.

SANI, G. (1981): «Partiti e atteggiamenti di massa in Spagna e Italia», Rivista Italiana di Scienza Politica, 11: 235-279.

- (1986): «Los desplazamientos del electorado: Anatomía del cambio», en J. J. Linz y J. R. Montero (eds.): Crisis y cambio: Electores y partidos en la España de los años ocbenta, Madrid: Centro de Estudios Constitucionales, pp. 1-26.

SAnI, G., y Montero, J. R. (1986): «El espectro político: Izquierda, derecha y centro», en J. J. Linz y J. R. Montero (eds.): Crisis y cambio: Electores y partidos en la España de los años ochenta, Madrid: Centro de Estudios Constitucionales, pp. 155-200. 
Sani, G., y Shabad, G. (1986): «¿Adversazios o competidores? La polarización del electorado», en J. J. Linz y J. R. Montero (eds.): Crisis y cambio: Electores y partidos en lo España de los años ochenta, Madrid: Centro de Estudios Constitucionales, pp. $587-624$.

Sani, G.; Gunt her, R., y Shabad, G. (1981): «Estrategia de los partidos y escisione: de masas en las elecciones parlamentarias españolas de 1979", Revista de Derecho Político, 11: 141-186.

Santamaría, J. (1982): «Transición controlada y dificultades de consolidación: El ejemplo español», en J. Santamaría (ed.): Transición a la democracia en el Sur de Europa y América Latina, Madrid: Centro de Investigaciones Sociológicas, pp. 371-417.

- (1984): «Elecciones generales de 1982 y consolidación de la democracia», RevisTa EsPAÑola DE INVESTIGACIONES SOCIOLÓGICAS, 28: 7-17.

Schumann, G. (1974): Konservatismus, Colonia: Kiepenheuer und Witsch.

Soria Medina, E. (1986): Elecciones de junio de 1986 en Andalucía, Sevilla: Editoriales Andaluzas Unidas.

VON BEYME, K. (1986): Los partidos políticos en las democracias occidentales, Madrid: Centro de Investigaciones Sociológicas/Siglo XXI. 